NISTIR 7403

\title{
Usability Testing of Ten-Print Fingerprint Capture
}

\author{
Mary Theofanos \\ Brian Stanton \\ Shahram Orandi \\ Ross Micheals \\ Nien-Fan Zhang \\ Information Access Division \\ Information Technology Laboratory
}

March 2007

National Institute of Standards and Technology

Technology Administration, U.S. Department of Commerce 
NISTIR 7403

\title{
Usability Testing of Ten-Print Fingerprint Capture
}

\author{
Mary Theofanos \\ Brian Stanton \\ Ross Micheals \\ Nien-Fan Zhang \\ U.S. Department of Commerce \\ Technology Administration \\ National Institute of Standards and Technology \\ Information Technology Lab \\ Gaithersburg, MD 20899
}

Shahram Orandi

MitreTek Systems

Falls Church, VA

March 2007

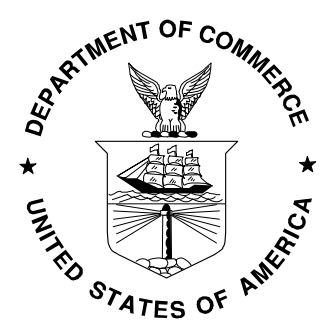

U.S. Department of Commerce Carlos M. Gutierrez, Secretary

Technology Administration Robert Cresanti, Under Secretary of Commerce for Technology

National Institute of Standards and Technology William Jeffrey, Director 


\section{Table of Contents}

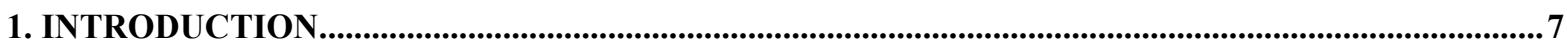

2. METHOD

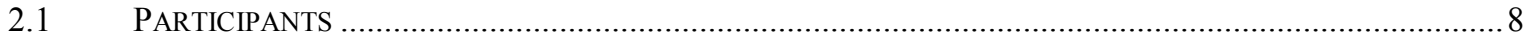

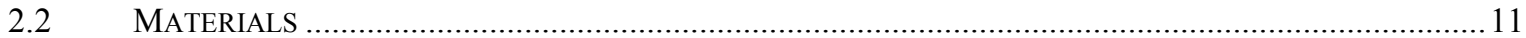

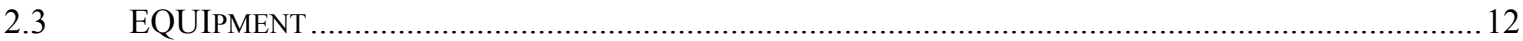

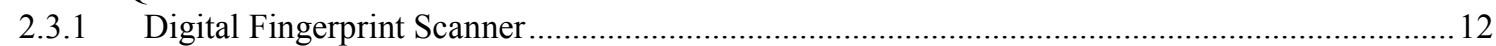

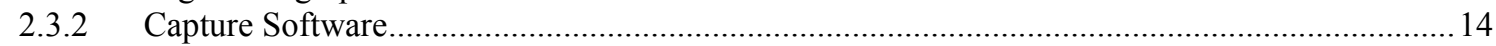

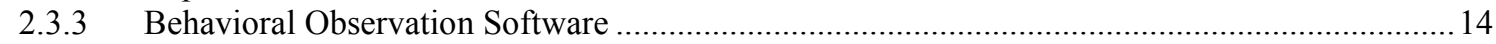

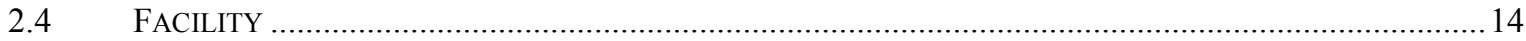

2.5 PROCEDURE

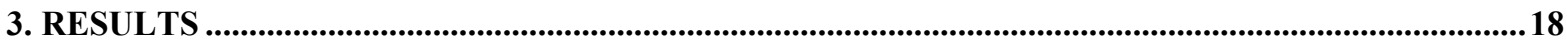

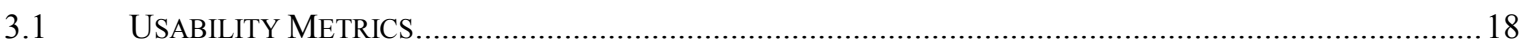

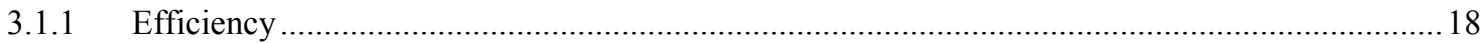

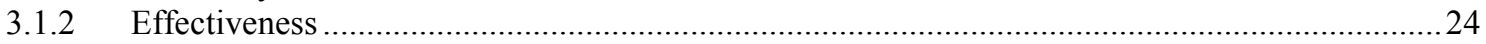

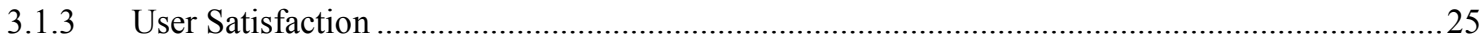

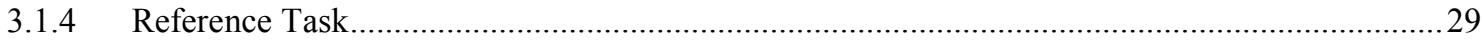

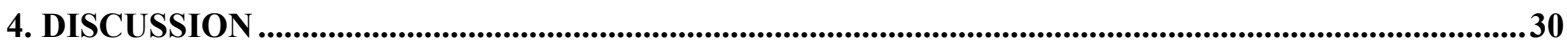

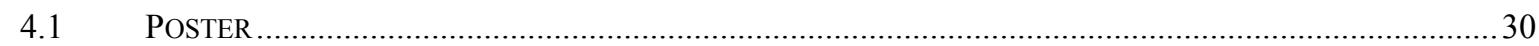

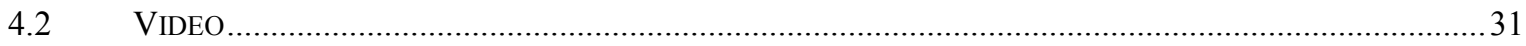

4.3 VERBAL

5. CONCLUSIONS AND FUTURE WORK ……...........................................................................................32

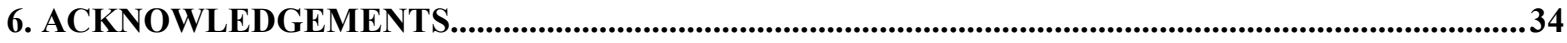

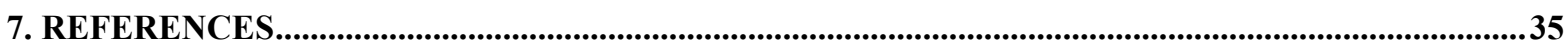

APPENDIX A: DEMOGRAPHIC QUESTIONNAIRE .................................................................................37

APPENDIX B: POST TEST QUESTIONNAIRE...........................................................................................39

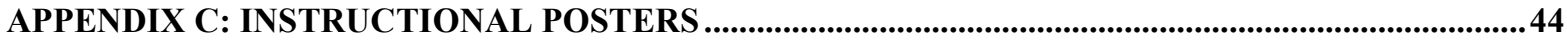

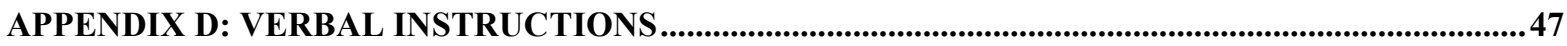

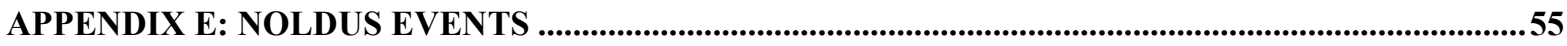




\section{$\underline{\text { List of Figures }}$}

FIGURE 1: US-VISIT SCANNER INSTRUCTIONAL PLACARDS (LEFT) AND INSTRUCTIONAL HANDOUT(RIGHT) ........7

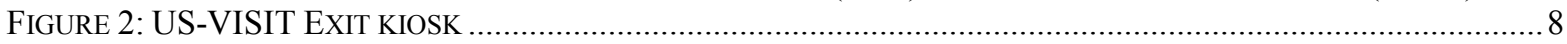

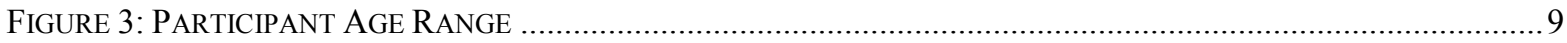

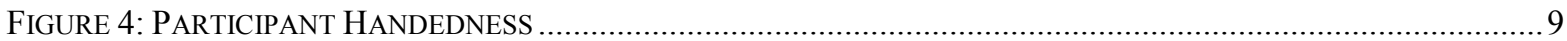

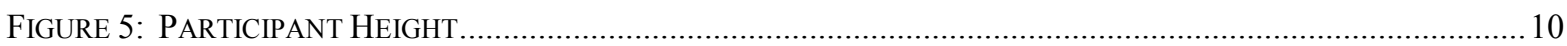

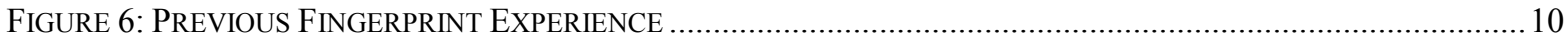

FIGURE 7: SURVEY QUESTION “HOW CONCERNED WERE YOU ABOUT HAVING YOUR FINGERPRINTS RECORDED?”

.

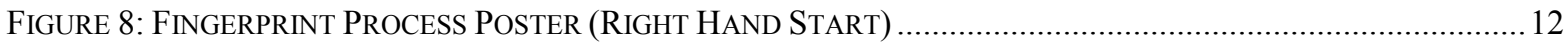

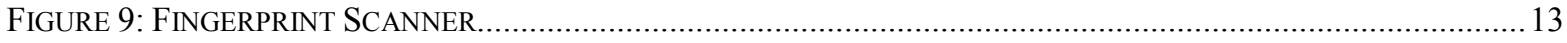

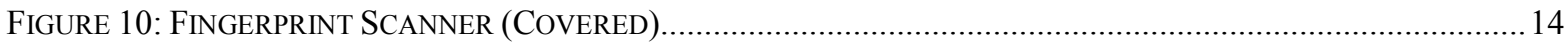

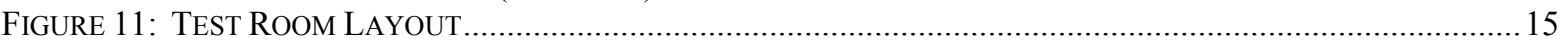

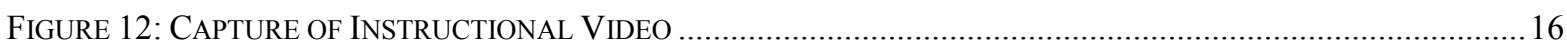

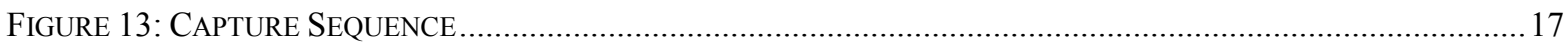

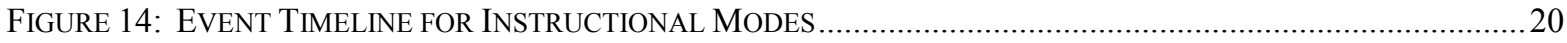

FIGURE 15: SURVEY QUESTION “THE INFORMATION PROVIDED WAS EFFECTIVE IN HELPING ME COMPLETE THE

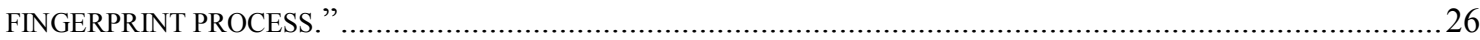

FIGURE 16: SURVEY QUESTION “THE INFORMATION PROVIDED WAS CONFUSING.”.............................................26

FIGURE 17: SURVEY QUESTION “IT WAS CLEAR WHICH HAND WAS TO BE SCANNED FIRST..”..................................2

FIGURE 18: SURVEY QUESTION “IT WAS CLEAR HOW TO POSITION YOUR HAND ON THE SENSOR.”.......................22

FIGURE 19: SURVEY QUESTION “THE ORDER OF FINGERPRINT CAPTURE WAS CLEAR.” .......................................2

FIGURE 20: SURVEY QUESTION “IT WAS CLEAR WHEN TO REMOVE YOUR HAND.” .............................................28

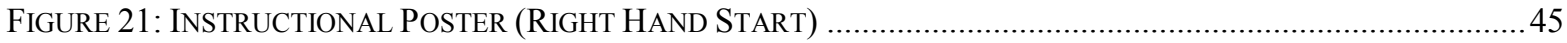

FIGURE 22: INSTRUCTIONAL POSTER (LEFT HAND START) .............................................................................. 46 


\section{EXECUTIVE SUMMARY}

The Department of Homeland Security (DHS) and the United States Visitor and Immigrant Status Indicator Technology (US-VISIT) program are migrating from a two print capture process (left and right index fingers) to a ten-print slap fingerprint capture process (all fingers on both hands). The NIST Biometrics Usability group performed a usability test to evaluate the time required to acquire a 10 print slap fingerprint image. Users accustomed with leaving two index fingerprints at US-VISIT may not be familiar with the ten slap fingerprint capture process. Thus, in addition to measuring the time necessary to acquire the 10 print slap, the study also evaluated various methods of providing instructional information to the users.

This report presents the results of a study that examined the 10-print collection process. The study was designed to answer three questions:

1. How long does it take to capture a 10-print image?

2. What is the impact of instructional mode (poster, verbal or video) on user performance?

3. What are the frequency and nature of the errors that occur in this process?

The experimental procedure may be summarized as follows. The participants were 300 adults recruited from a pool of 10,000 people. There were 151 women and 149 men ranging in ages from 18 to over 65 years. Each participant received instructions on how to complete the 10-print collection process in one of the three formats -- a $76 \times 115 \mathrm{~cm}$ poster, verbal instructions spoken by the test conductor, or a 50 second soundless video. The instructional materials portrayed three steps. Participants were asked to present a left slap, a right slap, and both thumb prints (simultaneously) according to the instructional materials. Participants were randomly assigned to either a right or left leading hand condition for one of the three instructional techniques.

Applying the definition of usability from the International Organization for Standardization (ISO) we measured efficiency, effectiveness, and user satisfaction. Efficiency was measured as the time required for a participant to complete the 10-print collection process including capturing a right-slap, left-slap and both thumb print images according to the instructions provided to the participant by one of the instructional methods. For each participant, the task was successfully completed if all three fingerprint images were captured. Effectiveness was measured by the number of participants who were unable to complete the task and by the number of errors incurred by the participants who successfully completed the task. Following collection of fingerprints, participants were asked questions about their satisfaction with the fingerprint process relative to the instructional modes provided.

This report describes four main results. 
1. Participants who received instructions via the poster had the most difficulty performing the fingerprinting task. Statistical analysis shows that participants who received the poster instructions took significantly longer to complete the 10-print collection process than participants in the video or verbal instructional groups. Fewer participants in the poster condition were able to complete the task and made significantly more errors than either the video or verbal conditions. Only $56 \%$ of these participants were able to successfully complete the fingerprinting process.

2. Participants who received the verbal and video instructions performed equally well. Verbal instructions were rated highest in preference by participants followed by video, and poster was rated the lowest of the three instructional modes. Verbal instructions may be difficult in an operational setting. Video instructions may be presented to many people waiting in line simultaneously providing an effective instructional delivery method by adding no additional time for the operator during the collection process and still providing optimum capture times and low-error incidence.

3. Operators are critical to the acquisition process. It appears that operators are able to assist individuals to overcome the deficits of the instructional materials. With operator assistance $98 \%$ of the participants were able to successfully complete the fingerprint process.

4. On average the time required to capture a 10-print sequence (a right slap, left slap and simultaneous thumbs) without operator assistance ranges from 48 to 64 seconds and the medians ranged from 45 to 59 seconds, and with operator assistance from 50 to 54 seconds (the medians ranged from 45 to 46 seconds) for our biometric system configuration The minimum time to successfully complete a capture sequence of the 3 images in our configuration is approximately 30 seconds. This includes approximately 21 seconds for image capture and 9 seconds of overhead for initialization and other operational chores. 


\section{INTRODUCTION}

The Department of Homeland Security (DHS) and the United States Visitor and Immigrant Status Indicator Technology (US-VISIT) program are migrating from a two print capture process (left and right index fingers) to a ten-print slap capture process (all fingers on both hands). This transition is based on recommendations from the National Institute of Standards and Technology (NIST) that were made in the joint report to Congress titled "Summary of NIST Patriot Act Recommendations" [NIST1]. The report indicated that "with available fingerprint scanning technology, the acquisition of 10 slap fingerprints should take only slightly more time than the acquisition of two flat fingerprints" [NIST1].

US-VISIT processing is currently based on a two-print capture process, the left and right index fingers of the individual. This is an operator assisted capture process with an experienced Customs and Border Protection (CBP) agent guiding each step of processing primarily using verbal instructions. In addition to assistance from the operator, some visual assistance is provided via placards that have symbols describing the fingerprint process as seen in Figure 1.
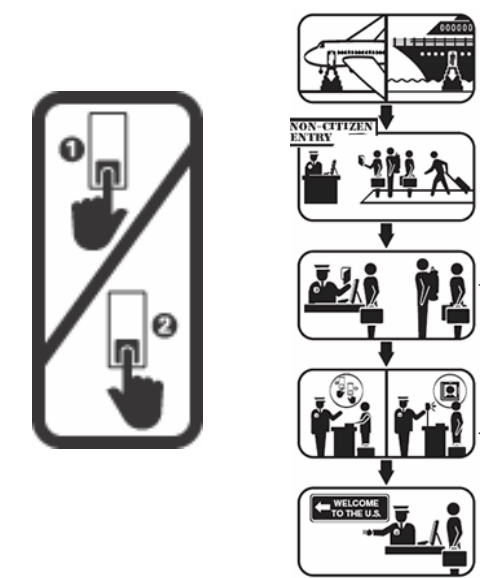

Figure 1: US-VISIT Scanner Instructional Placards (left) and Instructional Handout(right)

The US-VISIT exit procedure involves an unmanned kiosk that guides the user by written instructions as well as video/animation. In the exit procedure, digital fingerprints and photographs are again collected from the individual. 


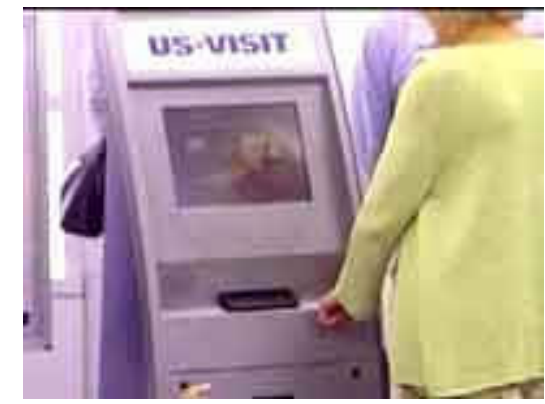

Figure 2: US-VISIT Exit kiosk

The NIST Biometrics Usability group performed a usability test to evaluate the time required to acquire a 10 print slap image ${ }^{1}$. Users accustomed with leaving two index fingerprints at US-VISIT may not be familiar with the ten slap fingerprint capture process. In addition to measuring the time necessary to acquire the 10 slap image, the study also evaluated how to present instructional information to the users. The study was designed to answer three questions:

1. How does the instructional mode (poster, video, or verbal) affect user performance?

2. How long does it take to capture a 10-print image?

3. What are the frequency and nature of the errors that occur in this process?

\section{METHOD}

\subsection{PARTICIPANTS}

The participants were 300 adults recruited from a pool of 10,000 people who had previously agreed to participate in usability tests. There were 151 women and 149 men ranging in ages from 18 to over 65 years.

\footnotetext{
1 These tests were performed for the Department of Homeland Security in accordance with section 303 of the Border Security Act, codified as 8 U.S.C. 1732. Specific hardware and software products identified in this report were used in order to perform the evaluations described in this document. In no case does such identification imply recommendation or endorsement by the National Institute of Standards and Technology, nor does it imply that the products and equipment identified are necessarily the best available for the purpose.
} 


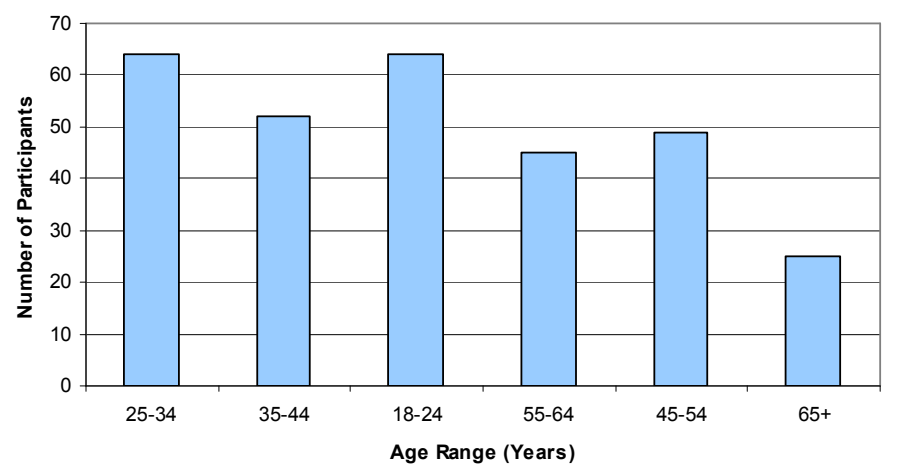

Figure 3: Participant Age Range

Of the 300 participants, 265 were right handed, 31 left handed, two ambidextrous, and two did not respond. As representative of the general population most of the participants were right-handed at $89 \%$, while $11 \%$ were either left-handed or ambidextrous. Available research shows that approximately $87 \%$ of the general population is right handed with the remaining $13 \%$ of the population either left handed or ambidextrous.[PORAC]

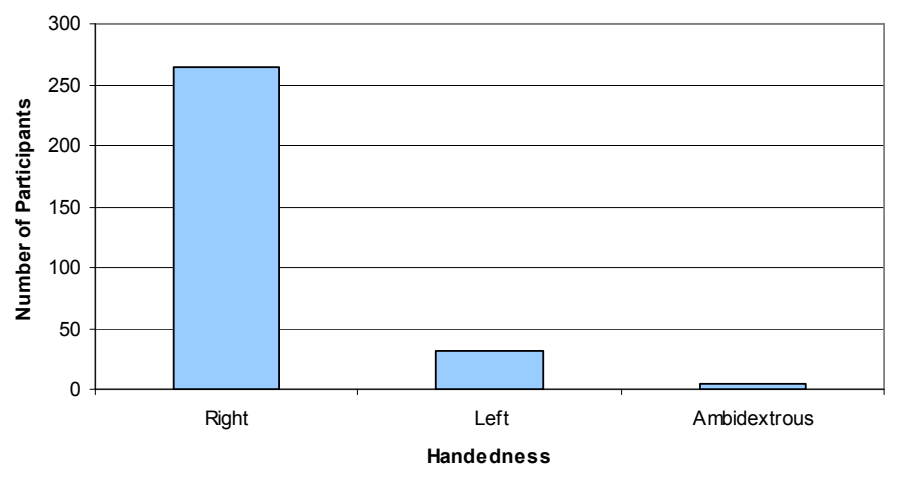

Figure 4: Participant Handedness

The participants ranged in self-reported height from 56 inches $(142 \mathrm{~cm})$ to 79 inches $(201$ $\mathrm{cm}$ ) with the range being fairly normally distributed with an average height of 70.2 inches $(178.3 \mathrm{~cm})$ for males and 64.4 inches $(163.6)$ for females. According to the Centers for Disease Control and Prevention (CDC) the mean individual height of men is 69 inches (175 $\mathrm{cm})$ and the mean individual height of women is 63 inches $(160 \mathrm{~cm})$ in the US[CDC]. The height data collected showed that our mean population height is within $2 \%$ of the mean in the US general population. According to the World Health Organization the worldwide mean individual male height is 5 feet 8 inches $(173 \mathrm{~cm})$ and the female height is 5 feet 2 inches $(158 \mathrm{~cm})$. 


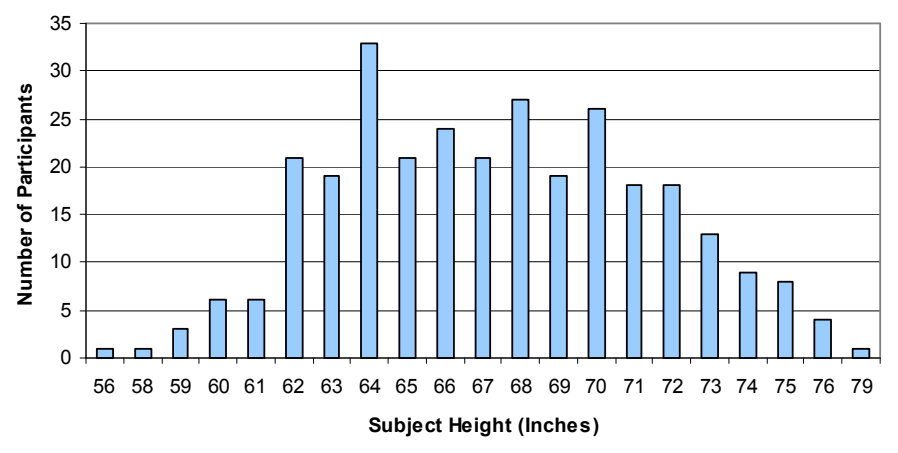

Figure 5: Participant Height

No participants worked in law enforcement or with fingerprints. All participants had self reported, normal color vision, and all ten digits. All participant spoke English fluently.

The participants indicated whether they had been previously fingerprinted.

Of the 300 participants $70 \%$ had been fingerprinted, only $9.7 \%$ had been electronically fingerprinted (see Figure 6). This is consistent with a telephone survey on public attitudes towards biometrics that was conducted in September 2001 where $69 \%$ had been fingerprinted and August 2002 where $66 \%$ had been fingerprinted [ORC].

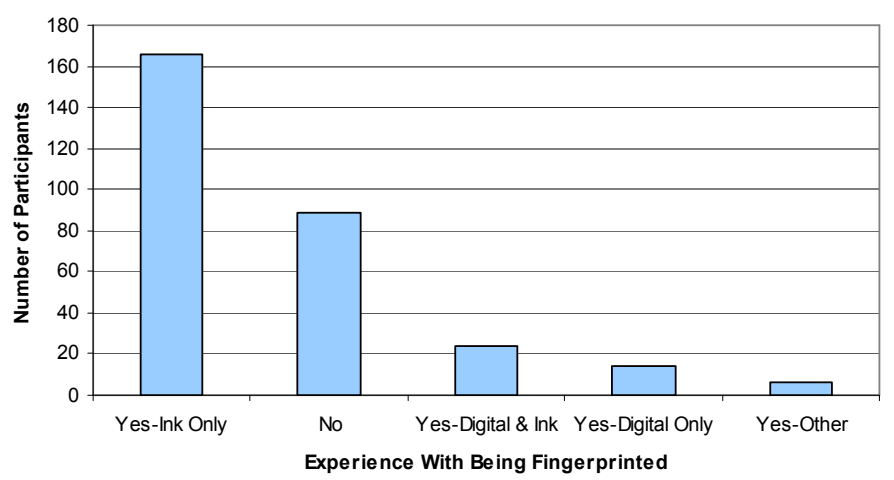

Figure 6: Previous Fingerprint Experience

Participants were also asked "How concerned were you about having your fingerprints recorded?" - Very concerned, Fairly concerned, Not very concerned, Not at all concerned, or Don't know. Of the 300 participants $84 \%$ were not at all or not very concerned about having their fingerprints recorded (see Figure 7). This is consistent with previous surveys that suggests that people have positive attitudes towards finger-imaging and are comfortable with biometric techniques [ORC]. 


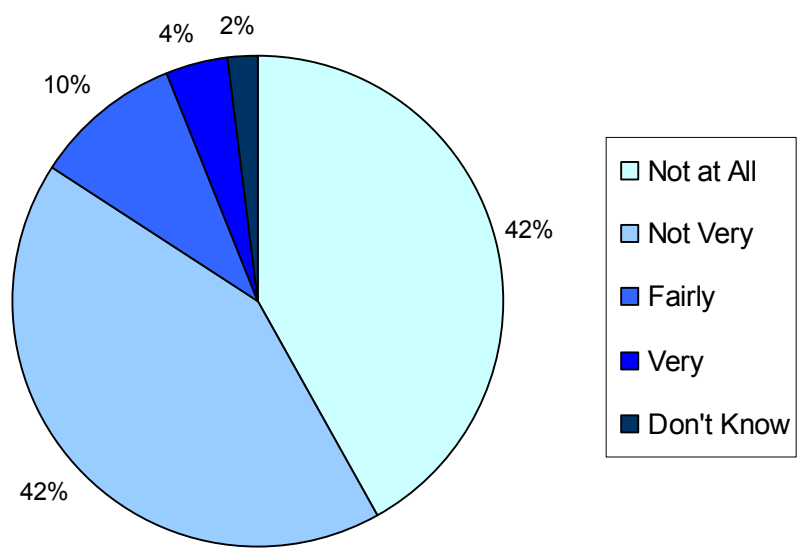

Figure 7: Survey Question "How concerned were you about having your fingerprints recorded?"

Finally participants were asked if they would be in favor or opposed to providing fingerprint images as a means of establishing identity for passport purposes. Of the 300 participants 230 or $77 \%$ were in favor or strongly in favor. This study's population mirrored the high acceptance for law enforcement to require fingerprint scans to verify identity for passports of the previous survey of $88 \%$ [ORC].

\subsection{MATERIALS}

Three different types of instructional materials were used. The participants were given instructions on how to give digital fingerprints via verbal instructions spoken by the test conductor (see Appendix D), a 50 second soundless video presented on a 17" monitor, or a $76 \times 115 \mathrm{~cm}$ poster (see Appendix C). The instructional materials portrayed three steps:

1. Presenting four fingers of the right hand (right slap),

2. Presenting four fingers of the left hand (left slap), and

3. Presenting both thumbs to the fingerprint sensor.

The start of the right slap step was indicated by the rightmost, of three, green Light Emitting Diodes (LEDs) illuminating. The start of the left slap step was indicated by the leftmost LED illuminating. The start of the thumbs step was indicated by the center LED illuminating. Each step ended when their respective LED darkened.

The three-slap capture process where thumbs are captured simultaneously as opposed to a four-slap capture process where thumbs are captured individually was selected because of the predominant use of the three-slap process by law enforcement. One of the reason for this 
popularity is because capturing both thumbs together can virtually eliminate the possibility of the user transposing the left and right thumb prints during the capture process.
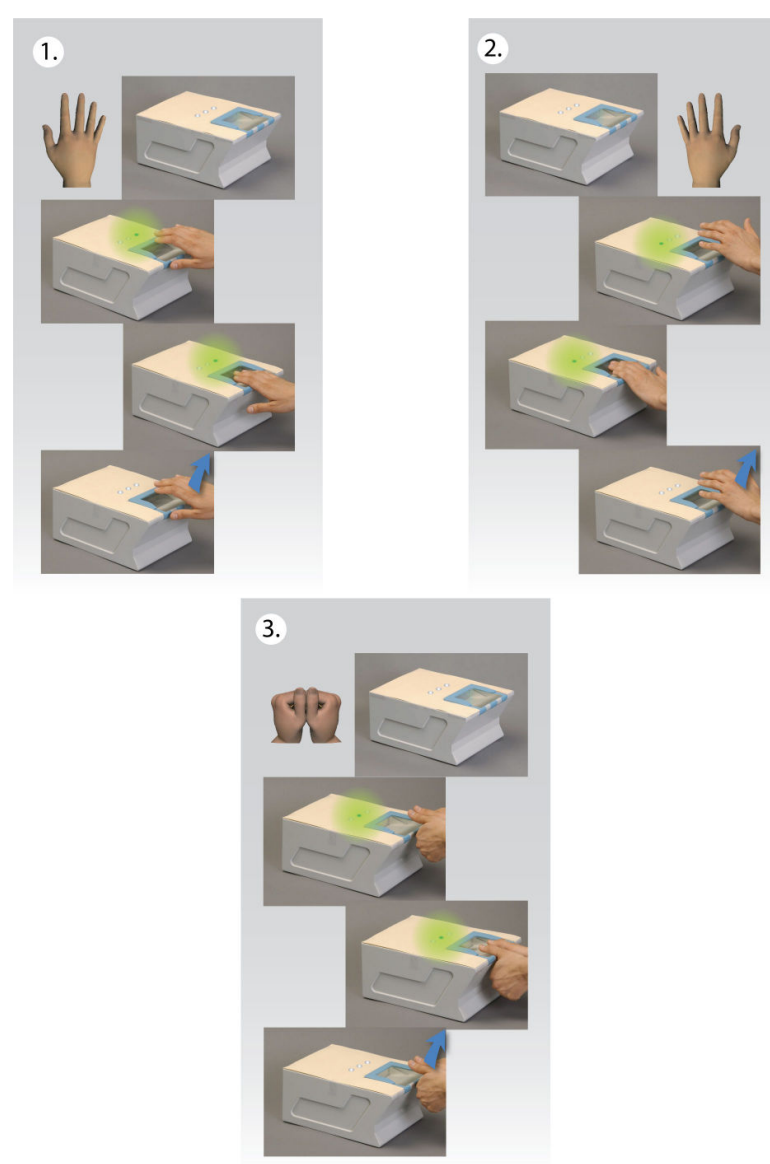

Figure 8: Fingerprint Process Poster (Right Hand Start)

There were two versions of each instructional material. One version started with a right hand and a second version started with a left hand.

\subsection{EQUIPMENT}

\subsubsection{Digital Fingerprint Scanner}

The digital fingerprint scanner selected for this experiment was the Smiths-Heimann (Crossmatch) LS2 Check digital fingerprint scanner [SHB] (see Figure 9). The LS2 scanner has a large 3.2 inch $\times 2.9$ inch platen $(81 \mathrm{~mm} \times 74 \mathrm{~mm})$ that allows for the capture of one or more fingers simultaneously. The LS2 scanner has a height of 6 inches $(152 \mathrm{~mm})$. There are three Light Emitting Diode (LED) indicators on the top surface of the scanner. These indicators are capable of red and green illumination. The scanner was situated on a work 
surface height of 36 inches $(914 \mathrm{~mm})$ which has been identified as an optimal height for the collection of ten-print slap images [NIST2].

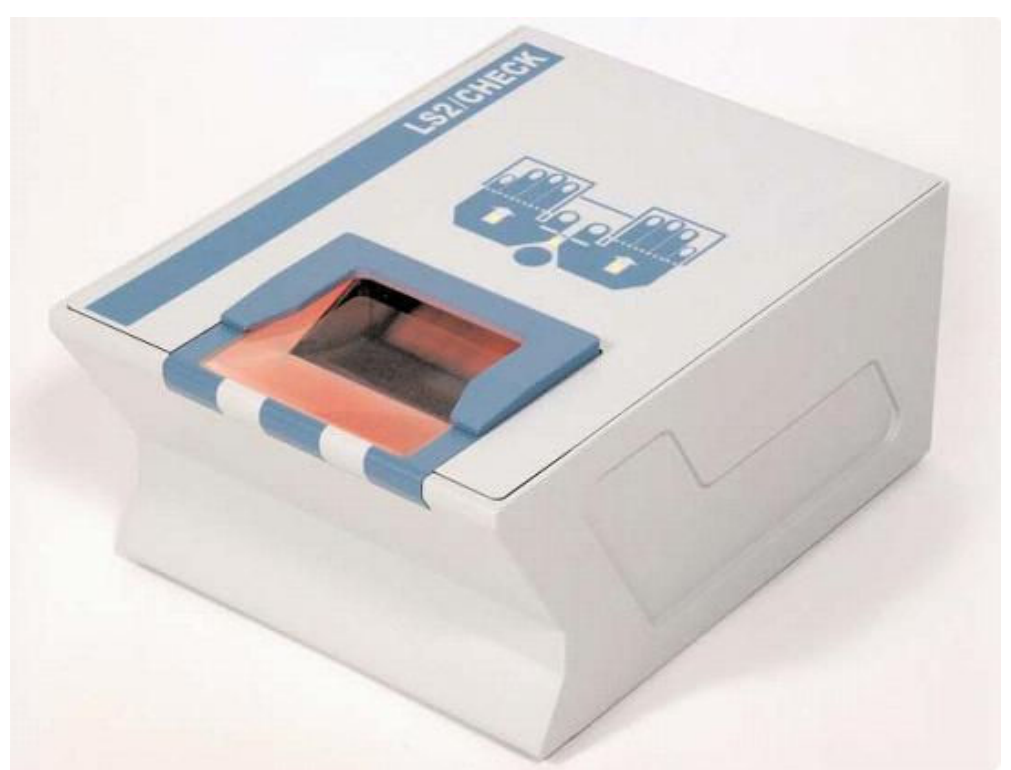

Figure 9: Fingerprint Scanner

The fingerprint scanner's top was covered by a piece of opaque paper to obscure any markings. The paper had openings cut into it to allow manual access to the scanner's platen and visual access to the three LED indicators (see Figure 10). 


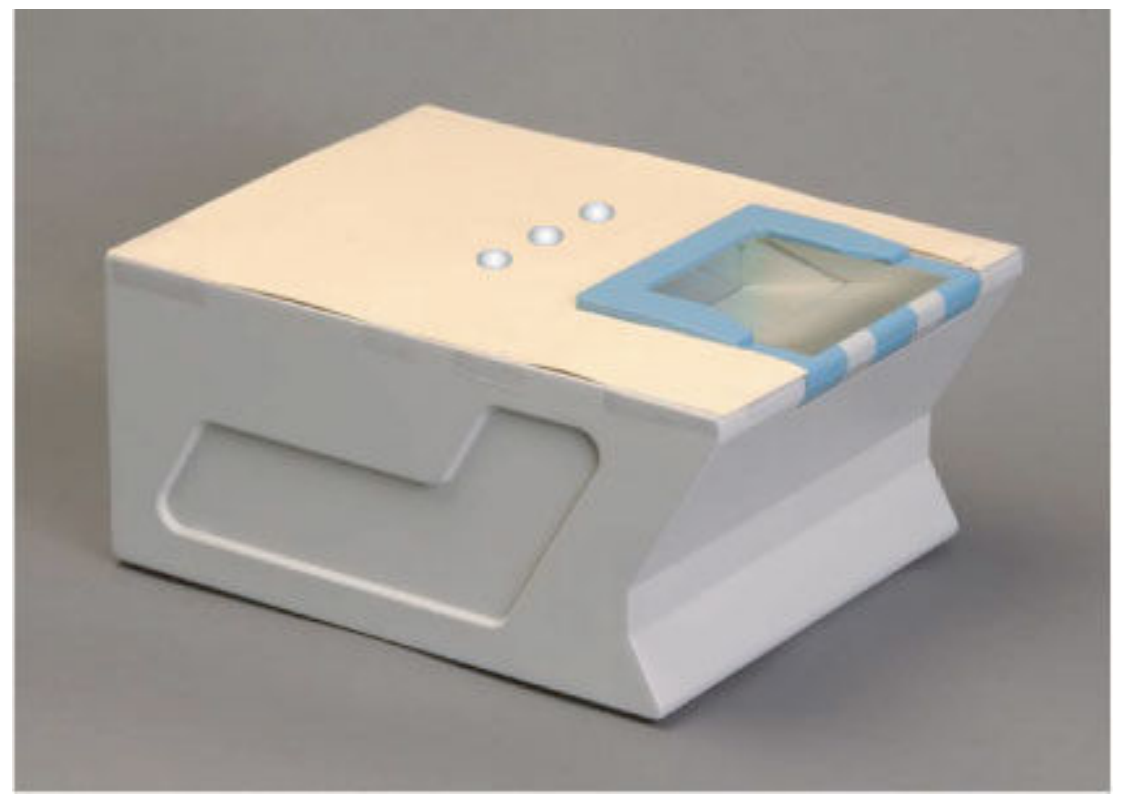

Figure 10: Fingerprint Scanner (Covered)

\subsubsection{Capture Software}

This experiment utilized the MBARK software package [NIST5] for controlled capture of images from a given participant. The custom software's high-level operational flow can be described in the following three steps:

1) Subject is prompted for a hand/finger combination

2) Once the hand/finger is detected, capture images for a set amount of time

3) Repeat step 2 for the next finger/hand combination until all combinations are complete

\subsubsection{Behavioral Observation Software}

Noldus Observer v5.0.31 running on Desktop PC and Noldus Pocket Observer v2.0 (handheld version) running on HP Ipaq 2495 PDAs were used to record errors and the timing of events.

\subsection{FACILITY}

The test was conducted in a usability testing facility consisting of two rooms separated by a one-way mirror. The participant, test conductor and scanner operator were in one room and an observer was in the other room (see Figure 11). 


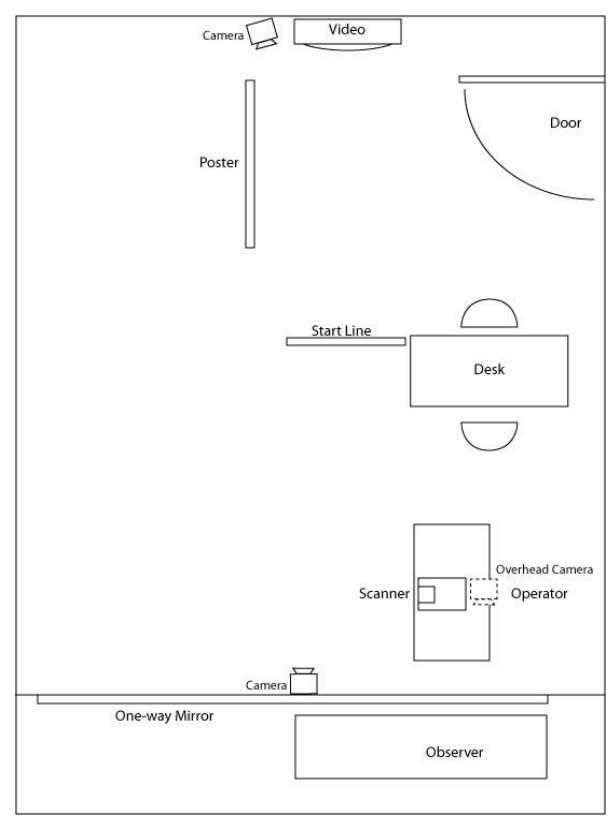

Figure 11: Test Room Layout

\subsection{PROCEDURE}

Each participant had three steps to complete. Participants were asked to present a left slap, a right slap, and both thumb prints (simultaneously). Participants were randomly assigned to either a right or left leading hand condition for one of the three instructional techniques.

\begin{tabular}{|c|c|c|c|}
\hline \multirow{2}{*}{ Instructions } & \multirow{2}{*}{ Participants } & \multicolumn{2}{|c|}{ Leading Hand } \\
\cline { 3 - 4 } & & Right & Left \\
\hline Verbal & 100 & 50 & 50 \\
\hline Poster & 100 & 50 & 50 \\
\hline Video & 100 & 50 & 50 \\
\hline
\end{tabular}

Table 1: 10 Print Experimental Design

Every participant was greeted and thanked for their participation. After a brief description of the fingerprint scanner, a consent and demographic form was filled out (see Appendix A). The participant was then given instructions on how to present their fingerprints by one of three techniques. In one condition the instructions were given verbally by the test conductor (see Appendix D for text). In the second condition the participant was shown a poster depicting the three presentations (right slap, left slap and thumbs). Each depiction of a presentation consisted of a picture for each of four stages (see Appendix C). The first picture showed the scanner with no LEDs illuminated. The second picture showed the scanner with an illuminated LED and the corresponding hand over the scanner platen. The third picture 
showed either fingers or thumbs pressing on the platen while the LED was illuminated. The fourth picture showed a non-illuminated scanner with a hand above the platen and a arrow, pointing upwards, over the hand. The third presentation technique consisted of a 50 second, silent, live action video of the three presentations. The video was framed so only the scanner and the hand was visible (see Figure 12). The participant pool for each instructional method was divided equally so half of the participants would receive a instruction that started with the right hand and the other half would receive instructions that started with the left hand.

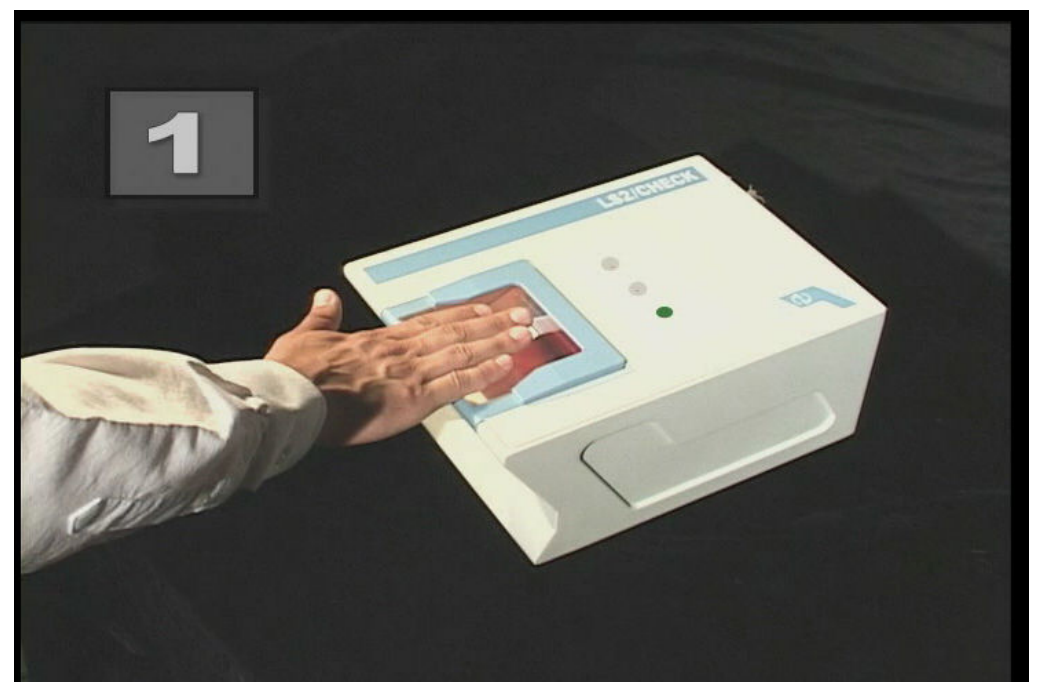

Figure 12: Capture of Instructional Video

Participants could receive the instructions as many times as they wanted and were asked if they had any questions after receiving instructions. Participants were instructed to walk over to the scanner area once they were satisfied with the instructions. The test conductor stopped the video or turned the poster away from the participant so neither could be seen from the fingerprint capture area. Once the participant was standing in front of the scanner, the operator started the scanner and indicated to the participant that they may begin. Depending on the experimental condition either the rightmost or leftmost LED on the scanner would illuminate. The scanning system would give the participant three opportunities to present for each step. Once a capture sequence was started the system would wait 25 seconds to sense if fingers were placed on the platen. If the system sensed fingers within the 25 seconds it would capture images for five seconds. At five seconds the system would check to see if it still sensed a hand. If it did sense a hand, the step was marked as successful, if not, an error was generated and the scanner would offer any remaining opportunities. If the system did not sense fingers on the platen within the 25 seconds, it would re-initiate the capture sequence up to three times. If nothing was sensed in three opportunities, the system would mark that step as unsuccessful and move on to the next step, as indicated by a new LED illuminating. A visual representation of this sequence is provided in Figure 13. 


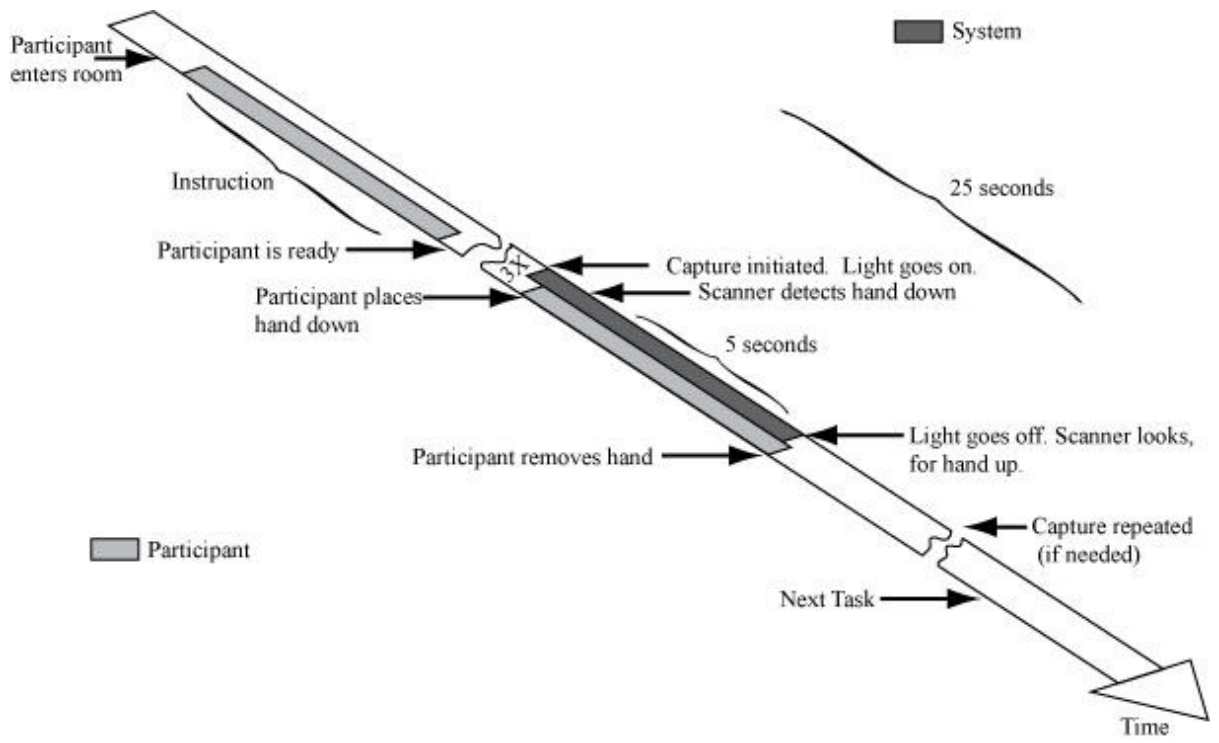

Figure 13: Capture Sequence

Using the Noldus systems, the test conductor and observer marked certain participant actions which the systems would timestamp (see Appendix E). The scanner software also created a time-stamped log of events.

After the completion of the fingerprint scanning the participant was asked to fill out a questionnaire (see Appendix B). 


\section{RESULTS}

\subsection{USABILITY METRICS}

According to ISO 9241-11 [ISO], usability is defined as "the extent to which a product can be used by specified users to achieve specified goals with effectiveness, efficiency and satisfaction in a specified context of use". The standard identifies three areas of measurement: effectiveness, efficiency, and user satisfaction, where

- efficiency is a measure of the resources expended in relation to the accuracy and completeness with which users achieve goals. Efficiency is related to productivity and is generally measured as task time

- effectiveness is a measure of the accuracy and completeness with which users achieve specified goals. Common metrics include completion rate and number of errors.

- user satisfaction is the degree to which the product meets the users' expectations - a subjective response in terms of ease of use, satisfaction, and usefulness.

In this study, we used the ISO definition and measured efficiency, effectiveness, and user satisfaction.

\subsubsection{Efficiency}

We measured efficiency as the time required for a participant to complete the task. A task is defined as capturing a right-slap, left-slap and both thumb prints images according to the instructions provided to the participant by one of the instructional methods. For each participant, the task was successfully completed if fingerprint images were captured for the three slaps

As described in the procedure section, the leading hand of the instruction sequence was counterbalanced. While it was determined later in analysis that there was no interaction between leading hand and any other factor. 
Due to hardware and software failures during the data collection process, timing data for several participants was found to be corrupt. Data was available for 284 participants of the 300 participants. Table 2 indicates the number of participants for each instructional method where data was completely available as well as the breakdown of leading hand start sequence provided by the instructional material to each group.

\begin{tabular}{|c|c|c|c|}
\hline $\begin{array}{c}\text { Instructional } \\
\text { Method }\end{array}$ & $\begin{array}{c}\text { Number of } \\
\text { Participants }\end{array}$ & $\begin{array}{c}\text { Instructions Start } \\
\text { With Right Hand }\end{array}$ & $\begin{array}{c}\text { Instructions Start } \\
\text { With Left Hand }\end{array}$ \\
\hline Poster & 96 & 46 & 50 \\
\hline Verbal & 90 & 51 & 39 \\
\hline Video & 98 & 50 & 48 \\
\hline
\end{tabular}

Table 2: Available data after elimination of corrupted trials

This subset of the population was further refined for this discussion by those participants where the three images were collected thus successfully completing the task. Of the 284 participants where data was available, 222 or $78 \%$ successfully completed the task. Table 3 indicates the number of participants for each instructional method that successfully completed the task.

\begin{tabular}{|c|c|}
\hline Instructional Method & Number of Participants \\
\hline Poster & 52 \\
\hline Verbal & 85 \\
\hline Video & 85 \\
\hline
\end{tabular}

Table 3: Participants who successfully completed the task

For completeness we identified a sequence of events that are required to complete the overall task from receiving the instructions to successful capture of fingerprint images. In addition to capturing the time required to complete the overall task we also measured the time required to complete these individual events or subtasks. These events are illustrated in Figure 14. Individual events include the presentation of the instructions, the approach to the sensor, and capturing the images. 


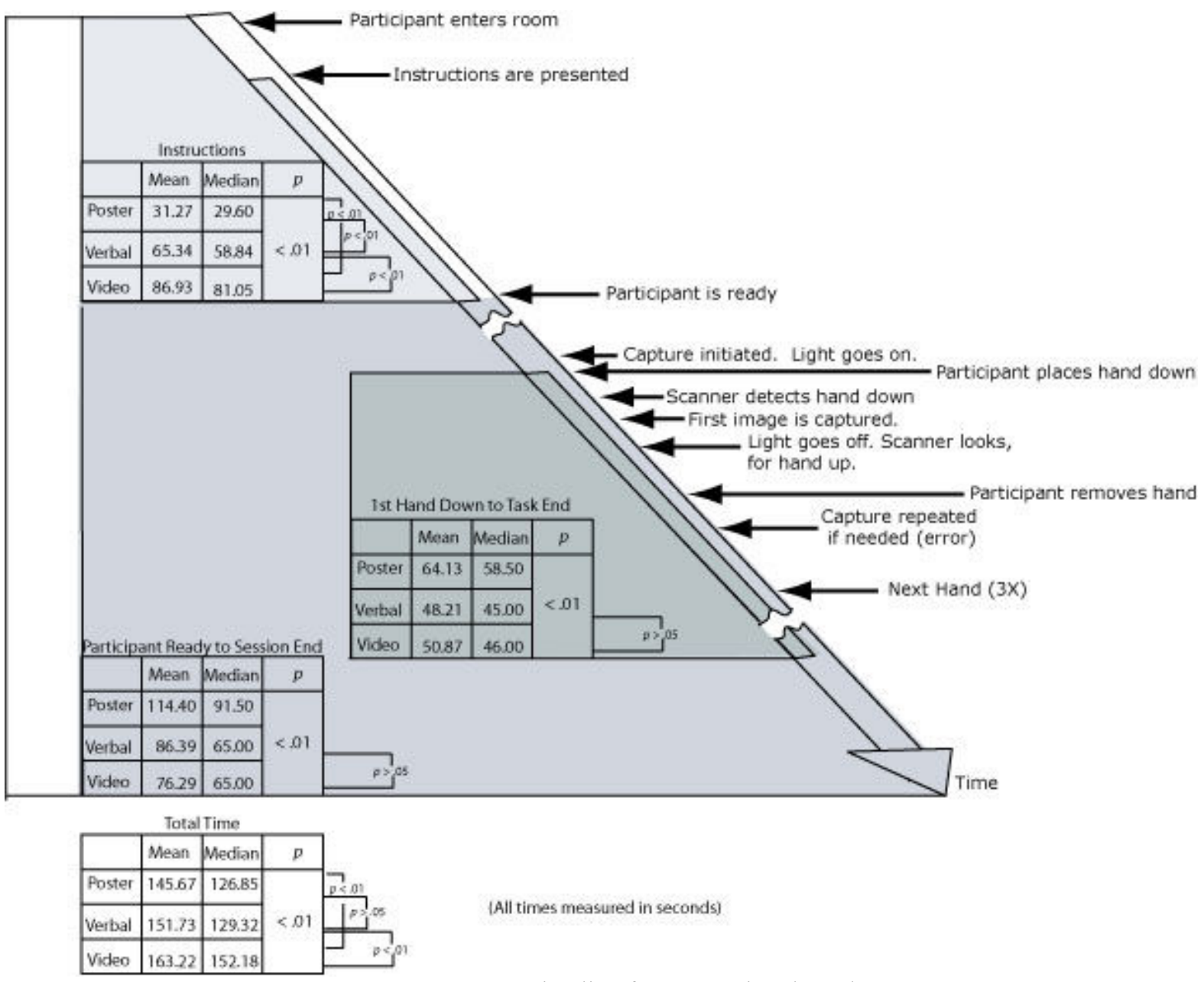

Figure 14: Event Timeline for Instructional Modes

\section{Presentation of Instructional Material}

The first event was the presentation of the instructional material. We measured this as the time the participant entered the room until he/she crossed a taped line on the floor. Once the participant crossed this line (Figure 11), he/she had clearly finished viewing the instructional materials. The mean and median times that participants required to receive each respective instructional method is provided in Table 4. The minimum time to receive the verbal instructions was approximately 45 seconds. The minimum time to view the video was 50 seconds. The minimum length of time the participants viewed the poster was at their discretion. 


\begin{tabular}{|c|c|c|}
\hline Instructional Method & Mean Time $(\mathrm{sec})$ & Median Time $(\mathrm{sec})$ \\
\hline Poster & 31.27 & 29.60 \\
\hline Verbal & 65.34 & 58.85 \\
\hline Video & 86.93 & 81.15 \\
\hline
\end{tabular}

Table 4: Time to receive instructional materials

A histogram with a normal probability density plot of task times showed that the data did not follow a normal distribution. This was verified by the Shapiro test for normality. All tests give $p$-values $<0.01$. It is clear these variable are definitely not normally distributed. Other tests such as the Chi-squared test and the tests based on skewness and kurtosis were also applied again, all give p-value $<0.01$.

Due to the non-normal distribution of the data the Kruskal-Wallis test and the median test were used to determine if the medians for the 3 methods are different. Both tests give a pvalue $<0.01$ indicating that the medians for the 3 methods are different. To complete the analysis, the Mann-Whitney test was used to test the pairs.

1. For Method 1 vs. Method 2 (poster vs. verbal), the medians of the two methods are statistically different, p-value $<0.01$.

2. For Method 1 vs. Method 3 (poster vs. video), the medians of the two methods are statistically different, $\mathrm{p}$-value $<0.01$.

3. For Method 2 vs. Method 3 (verbal vs. video), the medians of the two methods are statistically different, p-value $<0.01$.

Therefore, participants spent the least amount of time with the poster instructions, followed by the verbal instructions. Participants spent the most time with the video instructions .

\section{Approaching the Sensor and Capturing Images}

The second event was the approach to the sensor. This task time was measured from the time the participant crossed the taped line on the floor until the software application end. The mean and median time taken are presented in Table 5.

\begin{tabular}{|c|c|c|c|}
\hline Instructional Method & Number of Participants & $\begin{array}{c}\text { Mean Time } \\
(\mathrm{sec})\end{array}$ & $\begin{array}{c}\text { Median Time } \\
(\mathrm{sec})\end{array}$ \\
\hline Poster & 52 & 114.40 & 91.50 \\
\hline Verbal & 85 & 86.40 & 65.00 \\
\hline Video & 85 & 76.30 & 65.00 \\
\hline
\end{tabular}

Table 5: Time from approaching sensor to end of capture 
Due to the non-normal distribution of the data the Kruskal-Wallis test and the median test were used to determine if the medians for the three methods are different. Both tests give a $\mathrm{p}$-value $<0.01$ indicating that the medians for the three methods are different. To complete the analysis, the Mann-Whitney test was used to test different medians for Methods 2 and 3 (verbal and video) which resulted in a $\mathrm{p}$-value $>0.05$. Thus they are not different. The time to complete the tasks when given the poster is statistically significant from both the time to complete the task when receiving verbal and video instructions, but there is no significant difference between the task completion time for the video or verbal instructions.

\section{Capturing Images}

The third event was capturing the images. This time is measured from the software application capture start to the application capture end. The minimum time to successfully complete a capture sequence is approximately 30 seconds. This includes approximately 21 seconds for image capture and 9 seconds of overhead for initialization and other operational chores. The mean and median times are presented in Table 6.

\begin{tabular}{|l|c|c|c|}
\hline Method & Participants & Mean $(\mathrm{sec})$ & Median $(\mathrm{sec})$ \\
\hline Poster & 52 & 64.13 & 58.50 \\
\hline Verbal & 85 & 48.21 & 45.00 \\
\hline Video & 85 & 50.87 & 46.00 \\
\hline
\end{tabular}

Table 6: Time of software start capture and end capture

The Kruskal-Wallis test and the median test were used to determine if the medians for the 3 methods are different. Both tests give a $p$-value $<0.01$ indicating that the medians for the 3 methods are different. To complete the analysis, the Mann-Whitney test was used to test different medians for Methods 2 and 3 (verbal and video) which resulted in a $p$-value $>0.05$. Thus they are not different. Therefore, participants in the poster condition took significantly longer than either video or verbal conditions to complete the tasks.

\section{Total Time}

Finally, we measured the total time a participant took to complete the task, from receiving the instructions to end of capture. The mean and median times are presented in Table 7.

\begin{tabular}{|l|c|c|c|}
\hline Method & Participants & Mean $(\mathrm{sec})$ & Median $(\mathrm{sec})$ \\
\hline Poster & 52 & 145.67 & 126.85 \\
\hline Verbal & 85 & 151.73 & 129.32 \\
\hline Video & 85 & 163.22 & 152.18 \\
\hline
\end{tabular}

Table 7: Total Time 
Again, due to the non-normal distribution of the data, the Kruskal-Wallis test and the median test were used to determine if the medians for the 3 methods are different. Both tests give a $p$-value $<0.01$ indicating that the medians for the 3 methods are different. To complete the analysis, the Mann-Whitney test was used to test the pairs.

1. For Method 1 vs. Method 2 (poster vs. verbal), the medians of the two methods are not statistically different, $\mathrm{p}$-value $>0.05$.

2. For Method 1 vs. Method 3 (poster vs. video), the medians of the two methods are statistically different, $\mathrm{p}$-value $<0.01$.

3. For Method 2 vs. Method 3 (verbal vs. video), the medians of the two methods are statistically different, $\mathrm{p}$-value $<0.01$.

Therefore, the difference of the methods is based on the significant difference between poster and video and verbal and video.

\section{Error-free Image Capture}

In order to eliminate the effect of errors on the time required to capture images, we identified those participants who successfully completed the task with no errors. Of the 222 participants who successfully completed the task, 155 completed the task with no errors. Again, we measured the time to capture the images from the software application capture start to the application capture end. The minimum time to successfully complete a capture sequence is approximately 30 seconds. This includes approximately 21 seconds for image capture and 9 seconds of overhead for initialization and other operational chores. The mean and median times are presented in Table 8.

\begin{tabular}{|l|c|c|c|}
\hline Method & Participants & Mean $(\mathrm{sec})$ & Median $(\mathrm{sec})$ \\
\hline Poster & 17 & 59.20 & 55.00 \\
\hline Verbal & 68 & 46.10 & 45.00 \\
\hline Video & 70 & 47.60 & 44.00 \\
\hline
\end{tabular}

Table 8: Time of software start capture and end capture with no errors

Due to the non-normal distribution of the data, the Kruskal-Wallis test and the median test were used to determine if the medians for the 3 methods are different. Both tests give a $p$ value $<0.01$ indicating that the medians for the 3 methods are different. To complete the analysis, the Mann-Whitney test was used to test the pairs.

1. For Method 1 vs. Method 2 (poster vs. verbal), the medians of the two methods are statistically different, $\mathrm{p}<0.01$.

2. For Method 2 vs. Method 3 (verbal vs. video), the medians of the two methods are not statistically different, $\mathrm{p}$-value $>0.05$. 
3. For Method 1 vs. Method 3 (poster vs. video), the medians of the two methods are statistically different, $\mathrm{p}<0.01$.

Therefore, the difference of the methods is based on the significant difference between poster and video and verbal and video.

\subsubsection{Effectiveness}

In this experiment we measured effectiveness in two ways:

1. the number of participants who were unable to complete the task

2. the number of errors incurred by the participants who successfully completed the task.

Of the 284 participants for whom data was available, $78 \%$ were able to complete the task. The remaining 62 were unable to complete the task, meaning that they were unable to leave a left slap, right slap, and both thumb images. For each image these participants were given three attempts. Table 9 shows the number of participants that were unable to complete the task by instructional mode. The overwhelming majority (71\%) of participants who were unable to complete the task were in the poster condition.

\begin{tabular}{|c|c|}
\hline Instructional Method & Number of Participants \\
\hline Poster & 44 \\
\hline Verbal & 5 \\
\hline Video & 13 \\
\hline
\end{tabular}

Table 9: Subjects that did not successfully complete the task

Next we measured the number of errors incurred by the participant for each instructional mode for those that successfully completed the task. Thus the participant did not conform to the instructions but the attempt was acceptable (prints were captured)[NIST4] to complete the task within three tries for each stage. Errors included placing wrong hand on the scanner, lifting hand too soon, placing hand down too late, and a general error such as not placing a hand down at all. The following table shows the mean and median number of errors incurred. 
For the 222 participants that successfully completed the task, the Table 10 shows the number of errors incurred.

\begin{tabular}{|c|c|c|c|c|}
\hline $\begin{array}{c}\text { Instructional } \\
\text { Method }\end{array}$ & $\begin{array}{c}\text { Number of } \\
\text { Participants }\end{array}$ & $\begin{array}{c}\text { Mean Error } \\
\text { Count }\end{array}$ & $\begin{array}{c}\text { Median Error } \\
\text { Count }\end{array}$ & $\begin{array}{c}\text { Max Error } \\
\text { Count }\end{array}$ \\
\hline Poster & 52 & 2.02 & 2 & 8 \\
\hline Verbal & 85 & 0.29 & 0 & 3 \\
\hline Video & 85 & 0.33 & 0 & 3 \\
\hline
\end{tabular}

Table 10: Error Summary For Completed Cases

For error count, the Kruskal-Wallis test and the median test both give p-value $<0.01$ indicating that the medians for the 3 methods are different. The Mann-Whitney test was used to test different medians for Methods 2 and 3 with $p$-value $=0.82$. Thus they are not different.

Finally, of the 222 that successfully completed the task 155 or $55 \%$ completed error free trials. Table 11 shows the distribution by instructional mode. Fewer participants from the poster condition had error free tasks than either the verbal or video conditions.

\begin{tabular}{|l|c|c|}
\hline Method & Error Free & \% of Successful \\
\hline Poster & 17 & $33 \%$ \\
\hline Verbal & 68 & $80 \%$ \\
\hline Video & 70 & $82 \%$ \\
\hline
\end{tabular}

Table 11: Error Free Completion by Instructional Method

In conclusion, fewer participants in the poster condition were able to complete the task and made significantly more errors than either the video or verbal conditions. There is no significant difference between the error count for the video or verbal instructions.

\subsubsection{User Satisfaction}

Each participant was given a satisfaction survey after completing the test (See Appendix B for the actual questionnaire). The questions focused on the fingerprint process and the specific instructional mode provided.

The following 7 questions rating the instructional materials on a 5-point Likert-scale [LIKERT] where 1 was poor and 5 was good were answered by each participant:

1. The information provided was effective in helping me complete the fingerprint process.

2. The information provided clearly described the fingerprint process. 
3. The information provided was confusing.

4. It was clear which hand was to be scanned first.

5. The order of fingerprint capture was clear.

6. It was clear how to position your hand on the sensor

7. It was clear when to remove your hand.

Overall participants were satisfied with the instructions they were provided to complete the fingerprint process. The verbal instructions were rated highest by the participants followed by the video and the poster was rated the lowest of the three instructional modes. The verbal instructions were ranked the highest on all but one question. Participants ranked the video as clearer with respect to how to position your hand on the sensor than either the poster or the verbal instructions. Figure 15 through Figure 20 indicate the results of the 7 questions concerning the effectiveness and clarity of the instructional materials.

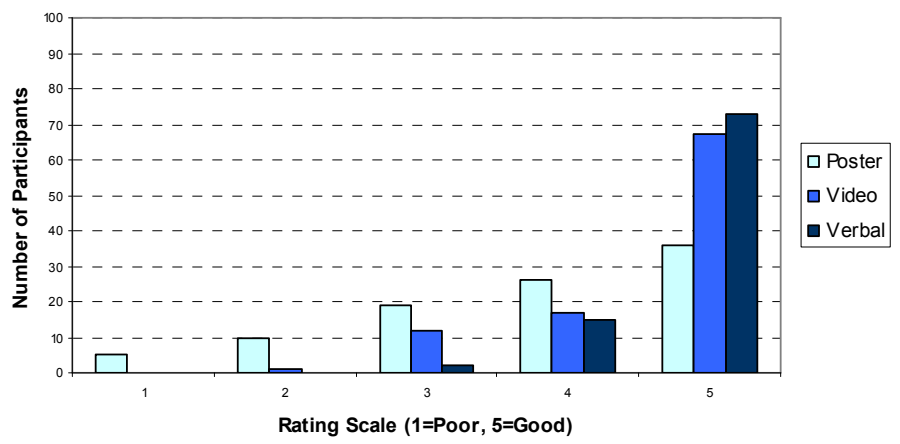

Figure 15: Survey Question "The information provided was effective in helping me complete the fingerprint process."

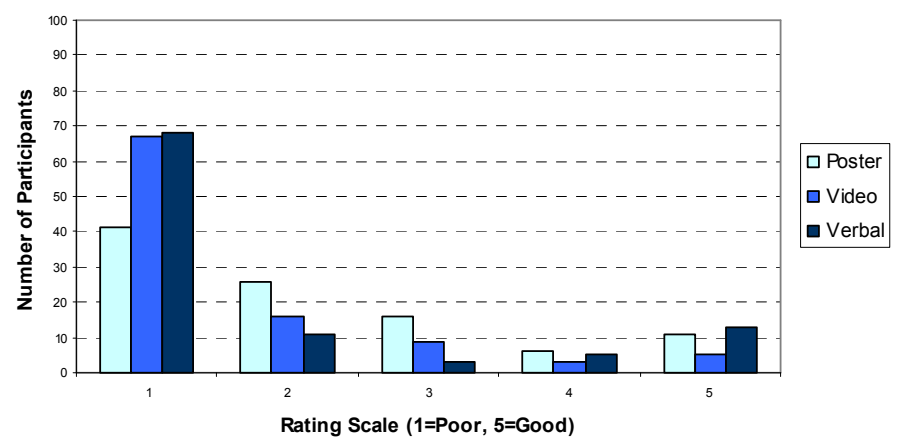

Figure 16: Survey Question “The information provided was confusing.” 


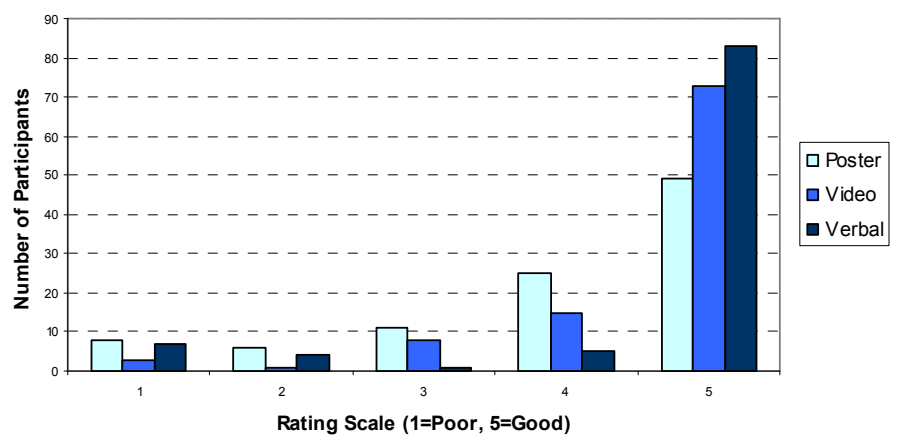

Figure 17: Survey Question "It was clear which hand was to be scanned first."

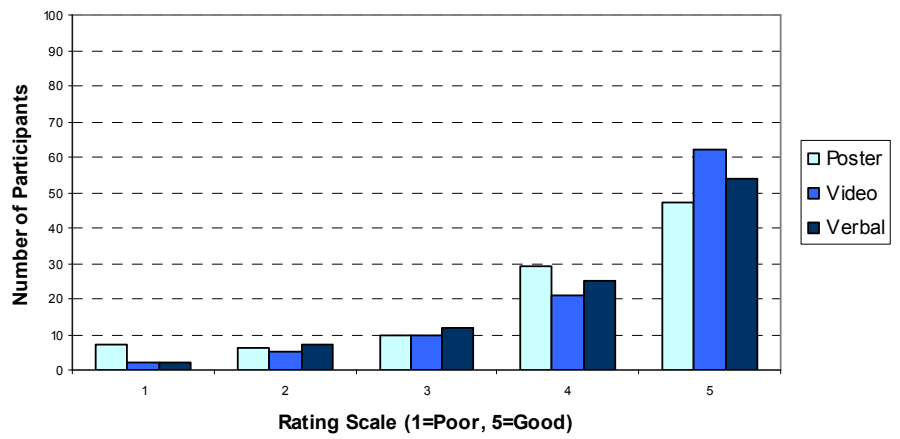

Figure 18: Survey Question "It was clear how to position your hand on the sensor."

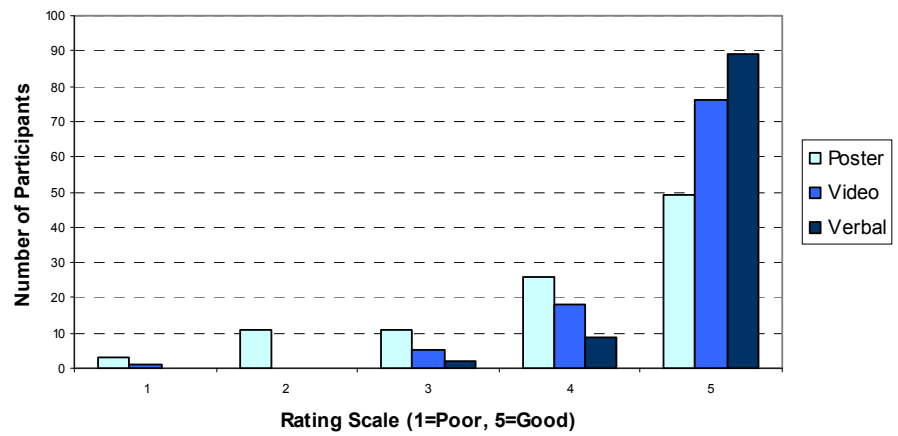

Figure 19: Survey Question "The order of fingerprint capture was clear." 


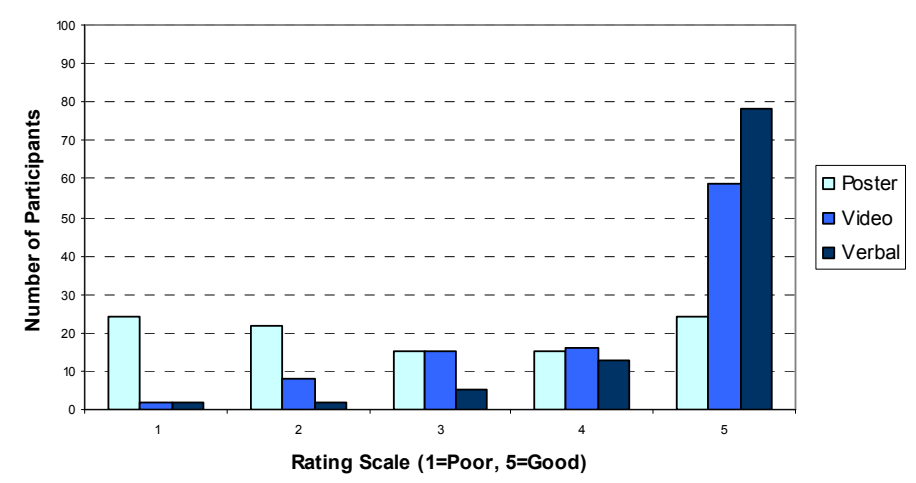

Figure 20: Survey Question "It was clear when to remove your hand."

After rating the instructional materials, the participants were asked two open-ended questions. First they were asked "What was the most confusing part of the process?" followed by "What additional information would you recommend to improve the fingerprint capture process?".

Most of the comments from the participants that viewed the poster revolved around when to remove their hand from the platen. Of the 100 participants that received the poster as the instructional material $39 \%$ commented that they were unsure when to remove their hand from the scanner. In addition, $20 \%$ commented that they missed or did not understand the lights. Fourteen percent of the participants mentioned that they were confused about how long to leave their hand on the scanner. Only 7\% commented on how to position their hand on the scanner. Many (37\%) suggested that adding text to the poster would be helpful. Seventeen percent responded that the green blinking light should be emphasized in order to indicate when to remove your hand, $10 \%$ recommended that the poster should include additional timing information.

Those who saw the video also commented that they were unsure of when to remove their hand from the scanner, but this time only $18 \%$ mentioned this, $11 \%$ commented that they were confused by the lights, and $9 \%$ were unsure how long to leave their hand on the scanner. However, 14\% mentioned that they were unsure how to position their hands on the scanner. Just as in the poster, many $45 \%$ suggested that the video should include text or audio. Another $20 \%$ indicated that the video or the scanner should emphasize how to position your hand. Only $7 \%$ felt the video needed to include timing information.

Most participants stated that the verbal instructions clearly described the tasks, $32 \%$ had no comments or complaints and $22 \%$ had favorable comments. Concern about how to position their hand on the scanner was mentioned by $20 \%$ of the verbal participants. Thus adding 
instructions on how to position your hand was suggested by $22 \%$ of the participants while $17 \%$ would include a visual element with the verbal instructions.

Finally, cleanliness of the scanner was an issue that several participants identified. About $2 \%$ of the participants did express concern about the cleanliness of the devices with which they would have physical contact. However, when participants were questioned about their thoughts on cleanliness, they indicated that they were not as concerned in this particular environment since it was a controlled laboratory setting. They assumed the platen was cleaned routinely and adequately. But they expressed concerns about the operational setting, indicating that they would immediately wash their hands or use a wet wipe after touching the fingerprint scanner [NIST3].

\subsubsection{Reference Task}

After completing the user satisfaction survey, participants were asked to repeat the fingerprint collection task. This second set of images is important in order to perform matches of images. This fingerprint task was operated assisted. Once again, we collected timing and error data. Time is measured from the software application capture start to the application capture end. The minimum time to successfully complete a capture sequence is approximately 30 seconds. This includes approximately 21 seconds for image capture and 9 seconds of overhead for initialization and other operational chores.

Of the 276 participants who agreed to repeat the collection process all but 7 were successful in completing the three steps. The timing and error data for the 269 participants who were successful in this second task is presented in Table 12 .

\begin{tabular}{|c|c|c|c|c|c|c|}
\hline Participants & $\begin{array}{c}\text { Instructional } \\
\text { Method }\end{array}$ & $\begin{array}{c}\text { Mean } \\
\text { Time } \\
(\mathrm{sec})\end{array}$ & $\begin{array}{c}\text { Median } \\
\text { Time }(\mathrm{sec})\end{array}$ & $\begin{array}{c}\text { Mean } \\
\text { Errors }\end{array}$ & $\begin{array}{c}\text { Median } \\
\text { Errors }\end{array}$ & $\begin{array}{c}\text { Max } \\
\text { Errors }\end{array}$ \\
\hline 269 & All & 52.63 & 46 & 0.17 & 0 & 5 \\
\hline 90 & Poster & 53.89 & 46 & 0.19 & 0 & 5 \\
\hline 87 & Verbal & 49.56 & 45 & 0.10 & 0 & 2 \\
\hline 92 & Video & 54.29 & 46 & 0.21 & 0 & 4 \\
\hline
\end{tabular}

Table 12: Error Analysis For Reference Task

We compared the timing data for the reference task in Table 12 to the timing data for the original task presented in Table 6 . The tables have been combined for convenience in Table 13. 


\begin{tabular}{|l|c|c|c|c|c|c|}
\hline Method & \multicolumn{3}{|c|}{ Original Task } & \multicolumn{3}{c|}{ Reference Task } \\
\hline & Participants & $\begin{array}{c}\text { Mean } \\
\text { Time }(\mathrm{sec})\end{array}$ & $\begin{array}{c}\text { Median } \\
\text { Time }(\mathrm{sec})\end{array}$ & Participants & $\begin{array}{c}\text { Mean Time } \\
(\mathrm{sec})\end{array}$ & $\begin{array}{c}\text { Median } \\
\text { Time }\end{array}$ \\
\hline Poster & 52 & 64.13 & 58.50 & 90 & 53.89 & 46.00 \\
\hline Verbal & 85 & 48.21 & 45.00 & 87 & 49.56 & 45.00 \\
\hline Video & 85 & 50.87 & 46.00 & 92 & 54.29 & 46.00 \\
\hline
\end{tabular}

Table 13: Comparison of Medians for Original and Reference Task

To complete the analysis we used a Mann-Whitney test.

1. For the poster, the medians of 58.50 and 46.50 are different with a p-value $<0.01$

2. For the verbal condition, the medians of 45.00 and 45.00 are not different, p-value $>$ 0.05 .

3. For the video condition, the medians of 46.00 and 45.00 are not different, p-value $>0.05$.

For this operator assisted second task $97 \%$ of the participants were able to successfully complete the task compared to $78 \%$ for the first task. Overall those in the poster condition committed fewer errors and completed the task faster than the original task.

\section{DISCUSSION}

This study was designed to examine the impact of instructional mode on user performance. In particular the goals were to determine:

1. How the instructional mode (poster, video, or verbal) affected user performance?

2. How long it took to capture a 10-print image? and

3. What were the frequency and nature of the errors that occurred in this process?

We address these questions with respect to each instructional method.

\subsection{POSTER}

Participants who received instructions via the poster had the most difficulty performing the fingerprinting task. $54 \%$ of these participants were unable to successfully complete the fingerprinting process, those who did took longer and committed more errors. The reasons for these errors varied. Some of the participants stated that the poster offered too much information and did not inform them as to the most important parts. Therefore, participants remembered only certain pieces of information, neglecting others. The most common error 
made by these participants was removing their fingers before a capture had taken place. During the follow-up interviews participants explained that the poster either failed to show the importance of the green lights or failed to show that the green lights were flashing. Some participants noted that they failed to see the lights at all. Overall participants who removed their hand too quickly stated that the poster failed to articulate any timing information.

Participants also did not seem to notice from the poster that the lights on the fingerprinting device conveyed significant information in the fingerprint capture process. Participants who did notice the light were perplexed to see a blinking light on the device. They had not gleaned from the poster illustration that a blinking light was involved.

An important consideration with the poster is the short time that participants took to study it. Many times participants would only glance at the poster and then continue with the process. With the verbal or video presentations, participants were more inclined to wait until the instructions had run their course. Thus they spent more time concentrating on the instructions than when confronted with the poster. The lack of a time dimension of the poster instructions also led to some confusion as to the required length of time of the parts of the fingerprinting process. Many participants guessed at the time required to give the fingerprints.

A number of participants also stated that in the poster it looked as if the hand was pressing a button with the thumb before placing the hand on the scanner. This led to people looking for a button on the device and then experiencing confusion when they could not find it.

One persistent issue with regards to the poster instructions was that participants often expected further instructions to follow. There were multiple instances where the participant would view the poster, approach the fingerprint device, and then ask the operator for instructions. Once the operator informed the participant that he/she was not in a position to answer any questions, the participant would ask to see the poster again or simply explain that they only briefly viewed the poster as they expected further details.

\subsection{VIDEO}

Participants who viewed the video instructions generally performed well in the fingerprinting task. One problem identified by the participants was with the timing of the green light turning off. People stated they could not tell, or had to watch more than once to determine, if the light went off before or after the hand was removed. Participants seemed split in their opinions about the duration of the video. Some people stated the video was excessively long and that the critical information could be conveyed in a shorter version. Others stated that the fact the video was in real-time helped to inform them as to how long to keep their hands on the scanner. This information was derived independently from their realization about the purpose of the lights, as some people actually counted the seconds as the video played. 
Another problem associated with the video instructions, was that the hand in the video seemed to press a button with the thumb. They also noted that it would have been helpful to have been informed at the beginning of the video that there were three steps demonstrated in the video.

\subsection{VERBAL}

Participants overwhelmingly stated that the verbal instructions clearly described the task. In general, participants who received the verbal instructions fared better than those who were instructed by the poster. Some concerns raised by participants about the verbal instructions were that they seemed "too wordy" or that they were overly complicated.

The few mistakes made following the verbal instructions could be attributed to the lack of a frame of reference. Since all participants were using the device for the first time, the instructions were being read without any visual reference, therefore, leaving room for interpretation. The instructions inform the participant to place his/her finger on the scanner. They do not specify where on the scanner to place the fingers, and as a result some people placed their fingers on the plastic casing located behind the platen. During the follow-up interview participants stated that a lack of reference in regards to the green lights also created confusion during the instructions. Not having a sense of what the device would look like until they approached it also caused participants who were instructed verbally to take extra time inspecting the device, trying to relate what they were seeing to what they had previously heard.

\section{CONCLUSIONS AND FUTURE WORK}

This study examined the impact of instructional mode on user performance. In particular we examined the impact of poster, video, and verbal instructions on the time required to capture a 10-print slap as well as the number of errors incurred during the process For this study a 10-print slap capture includes a right slap, left slap and simultaneous thumbs images. This study was performed in a controlled environment. This controlled environment did not attempt to simulate a point of entry environment or the stress associated with traveling and encountering the fingerprint process.

From this study we observed four main results. First, participants who received instructions via the poster had the most difficulty performing the fingerprinting task. Only $56 \%$ of these participants were able to successfully complete the fingerprinting process. Participants who received instructions by poster and successfully completed the fingerprinting capture process took significantly longer and committed significantly more errors than participants receiving video or verbal instructions. Although the poster or placard is a cost effective method of providing information for the 2-print process, this study illustrates the challenges of 
depicting a dynamic process in a static medium for a more complex 10-print process. We took great care in developing the poster for this study. Numerous versions of the poster were developed as we iteratively tested each version with small test groups before finalizing the design.[NIST6] However, additional study is required to develop a family of static symbols that can be used selectively to depict dynamic processes if poster instructions are to be used at all.

Second, participants who received the verbal and video instructions performed equally well. While the verbal method may have been equally as effective as the video in providing optimal capture time and minimal error count, in this particular context, in an operational setting it may not always be possible to depend on verbal instructions due to language barriers. Moreover, the verbal instructions must be delivered to each participant individually, in this study the verbal instructions took approximately 45 seconds. With this in mind, the video instructions may be more conducive to the operational environment. Video instructions can be presented to all the participants at once as they wait in line. Video instructions may be the optimal method of instructional delivery providing for efficiency by adding no additional time for the operator during the collection process and still providing optimum capture times and low-error incidence.

Third, operators are critical to the acquisition process. It appears that operators are able to assist individuals to overcome the deficits of the instructional materials. Without the assistance of an operator $45 \%$ of the participants who received the poster were not able to complete the fingerprinting process correctly. Overall, only $78 \%$ were able to successfully complete the collection process without assistance compared to $98 \%$ with operator assistance. In addition, participants for the poster condition committed fewer errors and took less time when assisted by an operator.

Finally we measured the time required to capture a 10-print sequence-in this case a right slap, left slap and simultaneous thumbs. With our biometric system configuration and a five second capture time, the minimum time to successfully complete a capture sequence of the three images is approximately 30 seconds. This includes approximately 21 seconds for image capture and 9 seconds of overhead for initialization and other operational chores. On average without operator assistance the collection process ranged from 48 to 64 seconds while the medians ranged from 45 to 59 seconds, and with operator assistance the collection process ranged from 50 to 54 seconds and the medians ranged from 45 to 46 seconds. 


\section{ACKNOWLEDGEMENTS}

We thank Dick Horst and the staff of UserWorks, Silver Spring MD USA who conducted the testing and collected the data for this research. 


\section{REFERENCES}

[CDC] US Department of Health and Human Services Centers for Disease Control and Prevention. (2004). Advanced Data From Vital and Health Statistics (DHHS Publication No. 2005-1250-04-0467). Hyattsville, MD: Ogden C.L., Fryar C.D., Carrol M.D., Flegal K.M. Retrieved January 4, 2007, from http://www.cdc.gov/nchs/data/ad/ad347.pdf

[ISO] Ergonomic requirements for office work with visual display terminals (VDTs) - Part 11: guidance on usability, ISO 9241-11, 1998.

[LIKERT] Likert, R. (1932). A Technique for the Measurement of Attitudes, Archives of Psychology 140, 55.

[NIST1] National Institute of Standards and Technology. Summary of NIST Patriot Act Recommendations. Gaithersburg, MD. Retrieved January 4, 2007 from http://www.itl.nist.gov/iad/894.03/pact/NIST PACT REC.pd $\underline{\mathrm{f}}$

[NIST2] Theofanos, M., Orandi, S., Micheals, R.J., Stanton, B., Zhang, N.F. (2006). Effects of Scanner Height on Fingerprint Capture. National Institute of Standards and Technology. NIST IR 7382. Retrieved February 20, 2007 from http://zing.ncsl.nist.gov/biousa/docs/NISTIR 7382 Height S tudy.pdf

[NIST3] Theofanos, M. (2006). Health and Safety Perceptions of Biometric Devices. November 28, 2006. Retrieved February 20, 2007 from http://zing.ncsl.nist.gov/biousa/docs/Health_Safety.pdf

[NIST4] Micheals, R.J., Stanton, B., Theofanos, M., Orandi, S. A Taxonomy of Definitions for Usability Studies in Biometrics. National Institute of Standards and Technology. NIST IR 7378. Retrieved February 20, 2007 from 
http://zing.ncsl.nist.gov/biousa/docs/NISTIR_7378_Taxonomy_for _Biometric_Usability.pdf

[NIST5] National Institute of Standards and Technology. Multimodal Biometric Application Resource Kit. Gaithersburg, MD. Retrieved from http://www.itl.nist.gov/iad/894.03/nigos/mbark.html

[NIST6] Theofanos, M and Stanton, Brian. (2007). Development of Instructional Poster for Fingerprint Capture. Gaithersburg MD: US National Institute of Standards and Technology. Manuscript in preparation.

[ORC] Westin, A. (2002). Public attitudes toward the uses of biometric identification technologies by government and the private sector: Summary of survey findings. Opinion Research Corporation (ORC) International. Retrieved January 4, 2007, from http://www.search.org/files/pdf/Biometricsurveyfindings.pdf

[SHB] Smiths-Heimann LS2 Check Scanner Specifications (2005), Cross Match Corporation. Retrieved January 4, 2007, from http://www.shb-jena.com/Products/LS2 CHECK.pdf 
APPENDIX A: DEMOGRAPHIC QUESTIONNAIRE 


\section{Demographic Questionnaire}

1. Age
$\square 18$ to 24
25 to 34
35 to 44
45 to 54
55 to 64
$\square 65+$

3. Handedness

$\square$ Right Handed

$\square$ Left Handed

$\square$ Ambidextrous

\section{Gender}

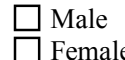

$\square$ Female
4. Height

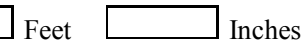

\section{Country of Origin}

7. Have you ever had your fingerprints captured before?

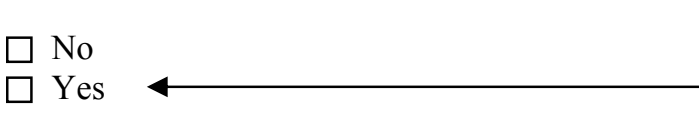

If you answered Yes, check all that apply:

$\square$ Fingerprinted electronically

$\square$ Fingerprinted with ink/paper

8. Before you took part in the trial how concerned were you about having your fingerprints recorded?

$\square$ Very concerned

$\square$ Fairly concerned

$\square$ Not very concerned

$\square$ Not at all concerned

$\square$ Don't know 
APPENDIX B: POST TEST QUESTIONNAIRE 


\section{Task Evaluation Questionnaire}

1. Was the level of intrusiveness you experienced during the fingerprint image recording more or less than you expected?
$\square$ Much more than expected
A little more than expected
$\square$ About the same as expected
$\square$ A little less than expected
$\square$ A lot less than expected
$\square$ Don't know

2. How did the time it took to have your fingerprint image recorded compare with what you expected?
$\square$ Much more than expected
$\square$ A little more than expected
$\square$ About the same as expected
$\square$ A little less than expected
$\square$ A lot less than expected
$\square$ Don't know

3. How would you rate the difficulty in positioning yourself so that your fingerprint image could be recorded?
$\square$ Much more than expected
$\square$ A little more than expected
$\square$ About the same as expected
$\square$ A little less than expected
$\square$ A lot less than expected
Don't know

4. Overall how did you feel about the experience of having your fingerprints taken?

Much better than expected

$\square$ A little better than expected 
About the same as expected

A little worse than expected

A lot worse than expected

Don't know

If you answered worse, can you please elaborate?

5. If fingerprint images were adopted as a means of establishing identity for passport purposes would you be in favor or opposed to providing an image of your fingerprints?

$\square$ Strongly in favor

$\square$ In favor

Neither in favor nor opposed

Opposed

Strongly opposed

Don't know

6. Rate the following questions on a 5 point scale with 1 being least favored and 5 most.

\begin{tabular}{|c|c|c|c|c|c|}
\hline \multirow[t]{2}{*}{ Question } & \multicolumn{2}{|l|}{ (:) } & \multicolumn{2}{|l|}{$\odot$} & : \\
\hline & 5 & 4 & 3 & 2 & 1 \\
\hline $\begin{array}{l}\text { The information provided was effective in } \\
\text { helping me complete the fingerprint process. }\end{array}$ & O & $\mathrm{O}$ & $\mathrm{O}$ & 0 & 0 \\
\hline $\begin{array}{l}\text { The information provided clearly described } \\
\text { the fingerprint process. }\end{array}$ & $\mathrm{O}$ & O & O & O & 0 \\
\hline The information provided was confusing. & O & O & $\mathrm{O}$ & O & $\mathrm{O}$ \\
\hline $\begin{array}{l}\text { It was clear which hand was to be scanned } \\
\text { first. }\end{array}$ & O & O & $\mathrm{O}$ & O & 0 \\
\hline The order of fingerprint capture was clear. & O & O & $\mathrm{O}$ & O & 0 \\
\hline $\begin{array}{l}\text { It was clear how to position your hand on the } \\
\text { sensor. }\end{array}$ & $\mathrm{O}$ & O & $\mathrm{O}$ & O & \\
\hline It was clear when to remove your hand. & O & O & $\mathrm{O}$ & O & \\
\hline
\end{tabular}


7. What was the most confusing part of the process?

9. Would information in another form be more helpful (rank order)

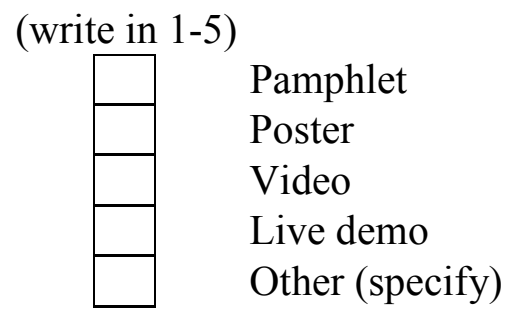

10. What additional information would you recommend to improve the fingerprint capture process?

NOTE: This survey contains collection of information requirements subject to the Paperwork Reduction Act. Notwithstanding any other provision of the law, no person is 
required to respond to, nor shall any person be subject to a penalty for failure to comply with, a collection of information subject to the requirements of the Paperwork Reduction Act, unless that collection of information displays a currently valid OMB control number. The estimated response time for this survey is $\mathbf{1 5}$ minutes. The response time includes the time for reviewing instructions, searching existing data sources, gathering and maintaining the data needed, and completing and reviewing the collection of information."

OMB no 0693-0043, expiration 07/31/09 
APPENDIX C: INSTRUCTIONAL POSTERS 

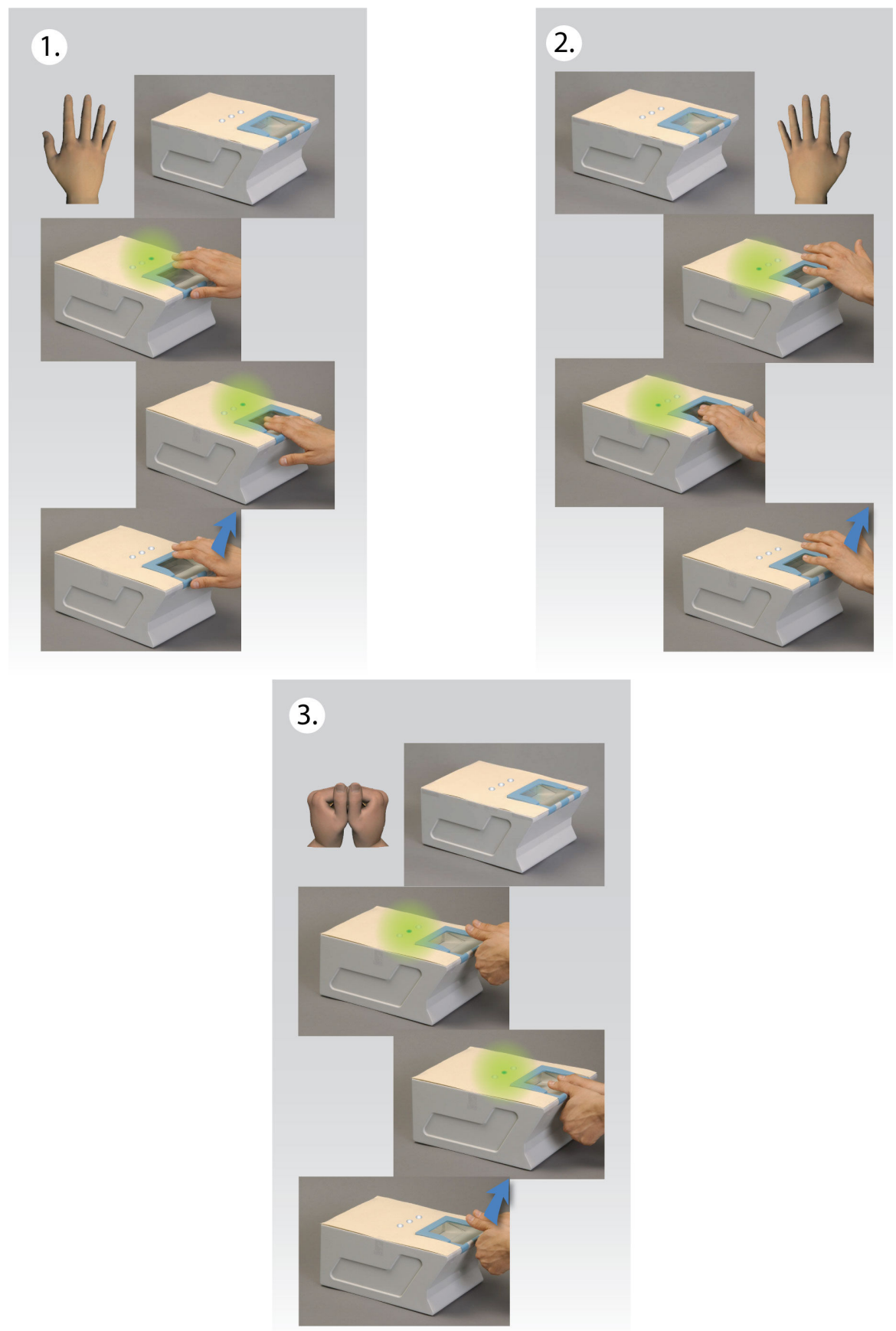

Figure 21: Instructional Poster (Right Hand Start) 

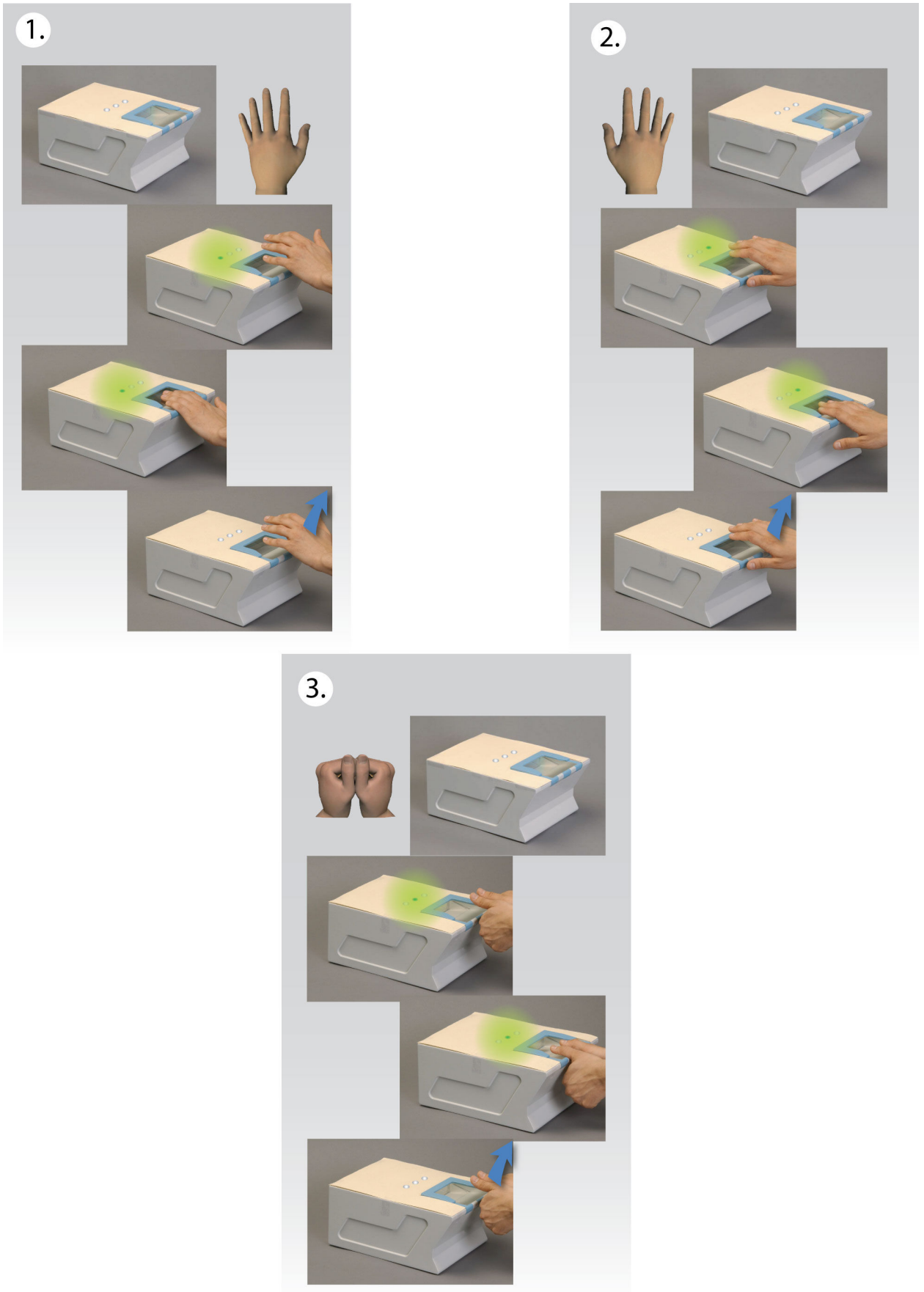

Figure 22: Instructional Poster (Left Hand Start) 
APPENDIX D: VERBAL INSTRUCTIONS 
The following test script was verbally presented to each participant in our study by the test system operator. Portions of this script that have been enclosed in brackets ("[" and "]") and are meant as special instructions for the operator. These special instructions guide the operator to tailor instructions for the specific participant or to have the operator perform certain actions.

[Welcome the participant]

"Thank you for taking the time to participate in our study today.

My name is [name] and we're interested in researching how long it takes for all ten fingerprints to be given, using an electronic digital fingerprint scanner. We are also interested in the process of taking Iris and Face images"

“Today's session will last approximately 30 minutes. If you want to stop at any time just say so."

\section{DESCRIBE EQUIPMENT}

"In our study, we'll be using a digital fingerprint scanner connected to a computer that detects and analyzes fingerprint images from the scanner.

You will be asked to use this scanner to give all ten of your fingerprints."

"There will be people observing the fingerprinting process so we can keep track of how long the different parts of the process take."

"Also, parts of the process will be video taped so that we can analyze it in more detail. However, we are not recording anything of you that can be use for personal identification purposes.

\section{Consent Form:}

\section{Demographic Form:}

\section{EXPLANATION OF TASKS}

"You will be presented with the instructions on how to use the scanner to give your fingerprints. After you feel that you understand the instructions, proceed to the operator with your papers."

"Do you have any questions before we begin?" 
If yes: (answer questions or explain again. No mention of the three instructional techniques should be made to the participant or anything specific about the scanning process).

If no: take participant into instructional area

(Participant's actions are recorded via Noldus) 


\section{Right Hand first instructions:}

\section{Instructions to Participant:}

Leaving a 10-print image is simple and consists of three steps.

Step \#1: When the right most light starts flashing green; place your right four fingers (demonstrate what four fingers) on the scanner and press down. Hold your fingers in place until the green light stops flashing

Step \#2: When the left most light starts flashing green; place your left four fingers (demonstrate what four fingers) on the scanner and press down. Hold your fingers in place until the green light stops flashing

Task \#3: When the center light starts flashing green; place your 2 thumbs (demonstrate thumbs side by side) on the scanner and press down. Hold your fingers in place until the green light stops flashing.

Would you like me to repeat the instructions? 


\section{Left Hand first instructions:}

Leaving a 10-print image is simple and consists of three steps.

Step \#1: When the left most light starts flashing green; place your left four fingers (demonstrate what four fingers) on the scanner and press down. Hold your fingers in place until the green light stops flashing.

Step \#2: When the right most light starts flashing green; place your right four fingers (demonstrate what four fingers) on the scanner and press down. Hold your fingers in place until the green light stops flashing.

Task \#3: When the center light starts flashing green; place your 2 thumbs (demonstrate thumbs side by side) on the scanner and press down. Hold your fingers in place until the green light stops flashing.

Would you like me to repeat the instructions? 


\section{PRESENT 1 OF THREE INSTRUCTIONAL TECHNIQUES}

When the participant understands the instructions they go into scanning area.

\section{OPERATOR:}

1. Retrieves papers from participant.

2. Presses MBARK Start Capture (MBARK should be set up for the participant previous to this point)

3. Tells Participant "you may begin"

Capture process occurs ...

Questions that may occur:

1. During the instructional period, participant may ask "Can I begin now?" respond with "If you are ready, please continue".

2. Generally, if the participant asks any question about the directions for giving the prints (e.g., "how long should I leave my hand?"), respond with "You should perform as the instructions have indicated".

3. "What does the (...) light mean?" Don't explain "I'd be happy to explain at the end of the test.

4. "Is the scanner clean?" "Yes, we clean it between each participant"

5. "May I see the instructions again?" "You may see the instructions after the last scan"

6. "(Why is the scanner)/(Should the scanner be) warm?" "This is normal system behavior."

Actions that may occur:

The general rule is to only prompt and make corrections during the session if the participant communicates that a mistake was made.

\section{Participant attempts wrong task, but does not notice}

If the participant uses the incorrect hand, but does not notice, then make the appropriate corrections after the participant is finished presenting their fingerprints, but before the "End Session" button is clicked.

\section{Participant notices they have attempted the wrong task}

If the participant uses the incorrect hand and does notice, then the operator should take the appropriate action (such as canceling a capture if one was already in process) and ask the participant to "Please wait while I make a correction." 


\section{Participant thinks they have used the incorrect hand, but hasn't}

Tell the participant to continue with the rest of the tasks and that they can try again after completion of the first set of tasks. Operator starts a new session after completion.

\section{Participant leaves their hand on too long}

If the participant leaves their hand on the scanner for too long (and the red LED is flashing) the operator should say "You may remove your hand now."

\section{Participant lifts their hand too soon and goes on to next task without waiting for indication.}

If the participant lifts their hand(s) too soon, the operator should make no verbal correction. If the participant attempts to start the next task, before the system detects that they have lifted their hand(s) too soon, then

Allow participant to continue.

\section{Participant lifts their hand too soon then replaces the same hand.}

If the participant lifts their hand(s) too soon, then replaces hand before the critical period. Mark it as a Noldus error but the operator does not reject the capture.

\section{Participant assumes they are done}

If the participant assumes that they are (prematurely) finished with the session then the operator should stop the capture and ask the participant if they would like to try again (it is important that the participant does not feel they did something wrong, just we would like to collect another set of prints). Operator starts new session.

\section{Participant asks if they are done}

If the participant asks if they are finished with the session, and they are not, then "If you believe that you have successfully given the prints, then you are done." If the participant assumes that they are (prematurely) finished with the session then the operator should stop the capture and ask the participant if they would like to try again (it is important that the participant does not feel they did something wrong, just we would like to collect another set of prints). Operator stars new session.

\section{Timeouts}

Every capture has an associated timeout - the time during which a successful capture must take place, or the system will consider the attempt as failed. However, because a successful capture requires a span of time, then there is some critical time during which if the participant starts, a failure is inevitable. For example, if the system is configured to capture fingerprints for five seconds, and timeout in 30 sections, a subject that starts the task 28 seconds into the process cannot give a successful capture without timing out. 
If a capture process times out because the participant does not attempt the task during the allotted time, or if the system can not detect that a hand was placed on the scanner, then the operator should make no verbal correction and allow the system to continue to operate along its workflow. If the operator observes that the subject places their hand on the sensor during the critical time then the operator should prompt the participant to "Please try again."

4. Ends MBARK session (Noldus tracking stops)

\section{QUESTIONNAIRE}

"Thank you for your participation. That concludes the test."

"We have a brief questionnaire that we would like you to complete."

\section{Iris and Face Scan}

TBD

\section{CONCLUSION}

"Thanks again for taking the time to participate in our study."

"Do you have any comments or questions about today's test session?" 
APPENDIX E: NOLDUS EVENTS 


\begin{tabular}{|c|c|c|}
\hline Short Code & Code Description & Long Code \& Button Title in Noldus UI \\
\hline ENT & Subject enters room & RmEntr \\
\hline REA & Subject crosses ready line & RdyLine \\
\hline DOC & Subject hands paperwork to operator & DocsGivn \\
\hline ORE & Operator asks if subject is ready & OpAskReady \\
\hline SRE & Subject indicates he/she is ready & SubjRdy \\
\hline HLO & Left hand placed on scanner & Left On \\
\hline $\mathrm{HOF}$ & Subject removes hand(s) from scanner & Hnds Off \\
\hline $\mathrm{HRO}$ & Right hand placed on scanner & Right On \\
\hline THU & Subject places both thumbs on scanner & Thmbs On \\
\hline END & All three prints captured & End Task \\
\hline ER1 & Wrong hand placed on scanner & E-WrongHand \\
\hline ER2 & Hand lifted too soon & E-EarlyLift \\
\hline ER3 & General error & E-General \\
\hline QUE & Subject asks operator question & Question \\
\hline REV & Review tape at/around this time index & ReviewTape \\
\hline RLO & Red Light On & -------M-ROn \\
\hline GLO & Green Light On & ---------M-GOn \\
\hline ALO & All Lights Off & --------M-LOf \\
\hline $\mathrm{CSL}$ & Capture Start-Left Slap & ---------M-CapSL \\
\hline CSR & Capture Start-Right Slap & ---------M-CapSR \\
\hline CST & Capture Start-Thumbs & ---------M-CapST \\
\hline CFR & Capture Frame & --------M-CapF \\
\hline CEN & Capture End & ------M-CapE \\
\hline $\mathrm{CSS}$ & Capture Start Session & ---------M-CapSS \\
\hline CES & Capture End Session & ---------M-CapES \\
\hline $\mathrm{CHO}$ & Capture Hand(s) Off & ---------M-CapHO \\
\hline CCA & Capture Cancel & ---------M-CapC \\
\hline CPR & Premature Lift & ---------M-CapP \\
\hline TCO & Task correction & --------M-TskC \\
\hline INI & Initialization & ---------M-Int \\
\hline CTO & Capture Time-out & ---------M-CapT \\
\hline OST & Operator skips task & --------M-CapSK \\
\hline MGE & Generic MBARK event & --------M-Gen \\
\hline
\end{tabular}

Table 14: Noldus Event Codes 